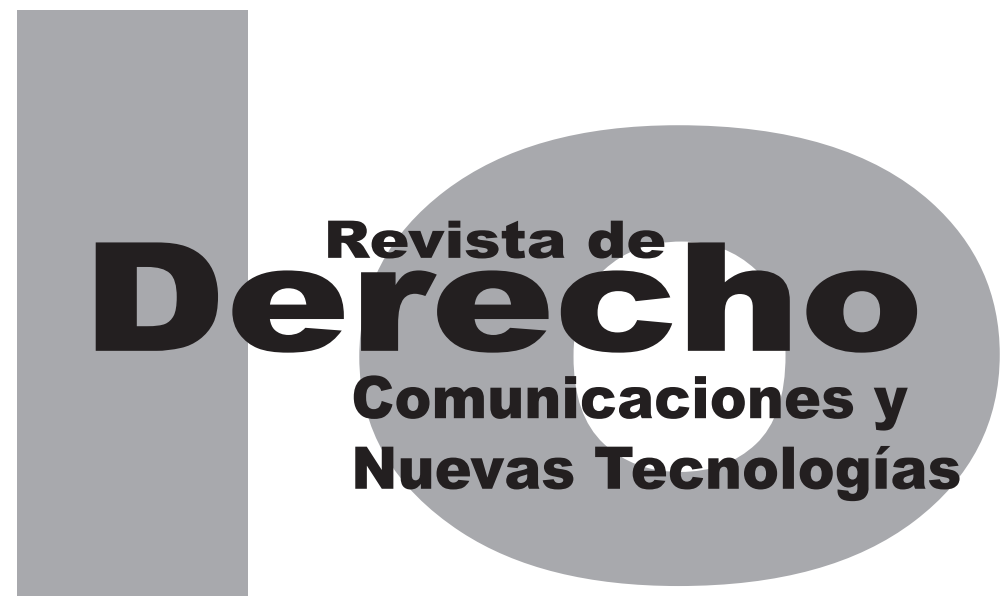

\title{
HISTORIA ESPACIAL: RECUENTO HISTÓRICO DE SU EVOLUCIÓN Y DESARROLLO
}

\author{
LAURA CORTÉS ROBAYO
}

Revisión de tema

DOI: http://dx.doi.org/10.15425/redecom.12.2014.05

\author{
Universidad de los Andes \\ Facultad de Derecho
}

Revista de Derecho, Comunicaciones y Nuevas Tecnologías

No. 12, Julio - Diciembre de 2014. ISSN 1909-7786 


\section{Historia espacial: recuento histórico de su evolución y desarrollo}

\section{Resumen}

Desde que el ser humano tiene la capacidad de pensar, ha sentido la necesidad de explicar lo que sucede a su alrededor, incluyendo lo que tiene lugar en el espacio ultraterrestre. Con este artículo se busca hacer una breve recopilación de los sucesos más importantes en la exploración espacial, que inició miles de años atrás con civilizaciones que actualmente ya no existen. Además, se busca exponer cómo tal exploración espacial pasó por un contexto de guerra, y a pesar de ello se hicieron avances significativos que mejoraron la calidad de vida de toda la humanidad. En otras palabras, se pretende presentar la manera como el hombre ha traspasado los límites de la Tierra para saciar su curiosidad. Por cuenta de ello, sigue dando pequeños pasos para cada día adentrarse más en el universo y tratar de entenderlo, así que se podría afirmar que el futuro está lleno de posibilidades inimaginables para la exploración espacial.

Palabras clave: exploración espacial, Segunda Guerra Mundial, Guerra Fría, carrera espacial, objeto espacial, cohetes, transbordadores, sondas, satélites, alunizaje, módulo lunar, planetas, astronautas.

\section{Space history: Historical account of evolution and development}

\section{Abstract}

Since humans beings have the ability to think, they have felt the need to explain what happens around them including what takes place in outer space. This article seeks to briefly summarize the most important events relating to the exploration of space; that began thousands of years ago, by civilizations which no longer exist. Furthermore, this article aims at expose highlighting how space exploration itself went through a phase of war, and despite this, significant advances have been made to improve the quality of life of all mankind. In other words, this article seeks to present the way men have pushed the boundaries of Earth to satisfy their curiosity, and doing so, have taken small steps each day in better understanding the mysteries of the universe. We can say that the future is full of unimaginable possibilities in the area of space exploration.

Keywords: space exploration, World War II, Cold War, space race, rockets, shuttles, satellites, probes, landing on the moon, lunar module, planets, astronauts.

\section{História espacial: reconto histórico de sua evolução e desenvolvimento Resumo}

Desde que o ser humano tem a capacidade de pensar, tem sentido a necessidade de explicar o que acontece ao seu redor, incluindo o que tem lugar no espaço ultraterrestre. Com este artigo se busca fazer uma breve recopilação dos acontecimentos mais importantes na exploração espacial que iniciou há milhares de anos atrás com civilizações que atualmente já não existem. Além disso, se busca expor como tal exploração espacial passou por um contexto de guerra, e apesar disso foram realizados avanços significativos que melhoraram a qualidade de vida de toda a humanidade. Em outras palavras, se pretende apresentar a maneira como o homem tem transpassado os limites da Terra para saciar sua curiosidade. Por conta disso, segue dando pequenos passos para cada dia adentrar-se mais no universo e tratar de entendê-lo, assim que se poderia afirmar que o futuro está cheio de possibilidades inimagináveis para a exploração espacial.

Palavras-chave: exploração espacial, Segunda Guerra Mundial, Guerra Fria, carreira espacial, objeto espacial, foguetes, balsa, sondas, satélites, alunissagem, módulo lunar, planetas, astronautas. 


\title{
Historia espacial: recuento histórico de su evolución y desarrollo*
}

\author{
Laura Cortés Robayo**
}

\section{SUMARIO}

Introducción - I. LAS PRIMERAS OBSERVACIONES DEL ESPACIO Y LOS CUERPOS CELESTES - A. Desde los antiguos hasta la invención del telescopio -II. EXPLORACIÓN ESPACIAL EN LA EDAD CONTEMPORÁNEA - A. Antecedentes de la carrera espacial - 1. La Segunda Guerra Mundial: la chispa inicial en la exploración del espacio ultraterrestre - 2. La Guerra Fría: inicio de la carrera espacial - 3. Viajes fuera de la Tierra: la carrera espacial - 4. Primeros pasos en la carrera espacial - 5. Destino: la Luna - 6. Sondas hacia otros mundos - 7. Exploración a los gigantes - 8. Transbordadores espaciales - 9. Vivir más allá de la Tierra - 10. El presente de la exploración espacial - III. ESFUERZOS EN LATINOAMÉRICA - IV. EL FUTURO DE LA EXPLORACIÓN ESPACIAL: ¿QUÉ NOS ESPERA? - V. CONCLUSIONES - Referencias.

\footnotetext{
* Cómo citar este artículo: Cortés Robayo, L. (Diciembre, 2014). Historia espacial: recuento histórico de su evolución y desarrollo. Revista de Derecho, Comunicaciones y Nuevas Tecnologías, 12. Universidad de los Andes (Colombia).

** Estudiante de sexto semestre de Derecho de la Universidad de los Andes. Directora general 2014-2 del proyecto web de Derecho del Espacio Ultraterrestre y alumna de la cátedra de Derecho del Espacio Ultraterrestre. Correo: I.cortes357@uniandes.edu.co
} 


\section{Introducción}

Desde que el hombre tiene uso de razón, ha sentido la necesidad de poder explicar los fenómenos que suceden a su alrededor $y$, por cuenta de ello, ha puesto sus ojos en el cielo tratando de revelar los misterios que se esconden en el oscuro profundo. Es así que poco a poco el ser humano ha intentado acercarse más a ese espacio ultraterrestre de una u otra forma. Evidencia de ello son las numerosas historias que varios escritores e incluso científicos han imaginado en relación con el espacio exterior. En 1865 el escritor francés Julio Verne publica su obra De la Tierra a la Luna en la que un proyectil llega a la Luna al ser lanzado por un cañón desde la Tierra (Educar.org). Esta novela de ciencia ficción en su momento pareció literalmente una locura, daba la impresión de que en ello se quedarían, en una historia fantástica, sin embargo, con el pasar de los años el hombre creó herramientas que le permitieron alcanzar eso que parecía imposible: Ilegar al espacio ultraterrestre y explorarlo. De esta manera, el ser humano observó que cada día llegaba más lejos en el espacio ultraterrestre y que en el marco de un conflicto como la Segunda Guerra Mundial o la Guerra Fría el dominio del espacio podría ser empleado con fines de destrucción que amenazarían la existencia de toda la humanidad. Por tanto, se vio la necesidad de crear instrumentos internacionales como la Declaración de los principios jurídicos que deben regir las actividades de los Estados en la exploración y utilización del espacio ultraterrestre y el Tratado sobre los principios que deben regir las actividades de los Estados en la exploración y utilización del espacio ultraterrestre, incluso la Luna y otros cuerpos celestes, los cuales de manera amplia señalan, principalmente, que el uso del espacio ultraterrestre se debe dar de manera pacífica. Sin embargo, no puede desconocerse todo el proceso histórico que tuvo lugar para que pudiera llegar a pensarse que era necesaria una regulación para las actividades que tuvieran lugar más allá de la Tierra. Precisamente ese es el propósito de este artículo, realizar un recuento histórico de los sucesos más importantes que han tenido lugar en la exploración, con ocasión del deseo que ha tenido el hombre de explorar el espacio ultraterrestre.

\section{LAS PRIMERAS OBSERVACIONES DEL ESPACIO Y LOS CUERPOS CELESTES}

\section{A. Desde los antiguos hasta la invención del telescopio}

Desde el inicio de su existencia, el hombre se ha interesado en la Luna, el Sol y las estrellas. Los sumerios, gracias a observaciones que hicieron al firmamento, calcularon la posición y el movimiento de los planetas, otorgaron nombres a las constelaciones del zodiaco, a los planetas, dieron explicación a las estaciones climáticas, vieron y predijeron eclipses. Ellos fueron quienes, además, dividieron el día en 24 horas, la hora en 60 minutos y los minutos en 60 segundos (Asosiación de amigos de la Astronomía). Por su parte, los antiguos egipcios crearon un calendario para celebrar sus festejos y contro- 
lar la crecida constante del Río Nilo, basados en los astros. De esta manera, la bóveda celeste se convirtió en un elemento crucial del paisaje en la cultura faraónica (Belmonte, 2013).

En cuanto a los griegos, varios pensadores se interesaron por los cuerpos celestes e hicieron importantes contribuciones al estudio de tales cuerpos. Eratóstenes fue el primer hombre en medir el tamaño de la Tierra; por su parte Aristarco de Samos fue el primer hombre en toda la historia en dar una propuesta para medir los tamaños y distancias del Sol y la Luna. De la misma manera, Pitágoras propuso que la Tierra era esférica. Luego, Aristóteles, el filósofo y pensador más influyente de su época, al igual que Pitágoras, afirmó que la Tierra era esférica, además de ello, logró entender la precisión de los equinoccios, lo que hizo que predecir los eclipses fuera más sencillo (Asosiación de amigos de la Astronomía). Y por último, pero no por ello menos significativo, se encuentra Hiparco, quien realizó observaciones con las que pudo determinar el período de rotación de los planetas, incluso agrupó un catálogo en el que esquematizó la posición de más de mil estrellas (Asosiación de amigos de la Astronomía).

Los mayas, por su parte, se interesaron especialmente en el Sol y por medio de operaciones matemáticas lograron descifrar la trayectoria que efectúa el Sol en el firmamento, enmarcada por las constelaciones zodiacales. Además, conocían los períodos heliocéntricos del Sistema Solar. Igualmente hay pruebas que señalan que los mayas también lograron predecir los eclipses (Asosiación de amigos de la Astronomía).
Con la llegada de la era moderna, tuvieron lugar importantes creaciones y descubrimientos. Muestra de ello fueron las observaciones realizadas por Nicolás Copérnico, quien señaló que el Sol es el centro de nuestro sistema solar, lo que constituyó un duro golpe al antropocentrismo. Sumado a esto, afirmó que los planetas son cuerpos celestes que giran en órbitas circulares en torno al Sol. Varias décadas después, Johannes Kepler notó que las órbitas de los planetas son elípticas y no circulares y propuso tres leyes respecto de la rotación de los planetas. ${ }^{1}$ Más tarde, en 1609, Galileo Galilei presentó su nueva creación en Venecia, un tubo con dos lentes que revolucionaría la manera de ver el mundo y conmocionaría a toda la sociedad, el telescopio. Más tarde, en 1611 el alemán Johannes Kepler fue el primero en usar dos lentes convexas que enfocaban los rayos en un mismo punto. La configuración de Kepler aún se usa en binoculares y cámaras fotográficas modernas y conforma la base del telescopio refractor (Posada-Awafford, 2009).

Teniendo en cuenta lo anterior, es evidente que el interés en el espacio viene desde hace miles de años atrás en la historia y que poco a poco se han hecho avances que acercan cada vez más al hombre a las estrellas.

\footnotetext{
Leyes de Kepler

1.- Cada planeta se mueve en una órbita elíptica con el Sol en uno de sus focos.

2.- La línea entre el Sol y un planeta recorre áreas iguales en tiempos iguales.

3.- El cuadrado del período de un planeta es proporcional al cubo del semieje mayor.
} 


\section{EXPLORACIÓN ESPACIAL EN LA EDAD CONTEMPORÁNEA}

\section{A. Antecedentes de la carrera espacial}

1. La Segunda Guerra Mundial: la chispa inicial en la exploración del espacio ultraterrestre

La Segunda Guerra Mundial fue un conflicto que involucró a la mayoría de países del mundo, principalmente a las grandes potencias. Durante esta pugna, el globo terráqueo se dividió en dos alianzas militares: las Potencias del Eje, conformado por Alemania, Japón, Italia y otros países. Por otro lado, los Aliados, constituidos por el Reino Unido e Irlanda del Norte, Francia, Estados Unidos y la Unión Soviética, quienes combatían contra las Potencias del Eje y sus intereses expansionistas (Portalplanetasedna. com.ar). La guerra que tuvo lugar acabó con la vida de millones de personas y dejó en ruinas a decenas de ciudades europeas. Específicamente y para efectos del presente trabajo, nos centraremos en la tensión entre Alemania y el Reino Unido de Gran Bretaña. La tensión entre ambas naciones nació luego de que Francia y el Reino unido declararan la guerra a Adolfo Hitler, jefe del Tercer Reich y artífice de los programas expansionistas en Europa (Enciclopedia Salvat, 1971), esto ocurrió, en seguida de que tuviera lugar la invasión nazi a territorio de Polonia el primer día del mes de septiembre de 1939. Como respuesta a ello la Italia fascista en cabeza de Benito Mussolini declaró la guerra a los británicos (Halifax, 1939).
Los ingleses en cabeza del primer ministro Winston Churchill se mantuvieron firmes en la lucha contra los nazis y por tal razón fueron los principales enemigos del Tercer Reich. Churchill no tenía como opción la rendición, por el contrario haría frente a los ataques alemanes y evidencia de ello fue la perseverancia con la que se mantuvieron en pie luego de que uno de sus aliados, Francia, se rindiera y firmara el Armisticio del 22 de junio de 1940 en el que se establecía un cese de hostilidades (EcuRed. cu). El Reino Unido logró superar la Batalla de Inglaterra, la cual constituyó una serie de ataques durante más de tres meses en los que la Alemania nazi buscó destruir a la Real Fuerza Aérea para lograr control aéreo y naval sobre las Islas Británicas y poder invadirlas; a ello se le denominó la «Operación León Marino». Luego de intensas semanas de combate aéreo, en los que los ingleses se vieron acorralados ante el bombardeo de los alemanes a los aeródromos en Tierra, Churchill ideó un plan disuasivo en el que bombardearía Berlín para que los alemanes desistieran de atacar los aeródromos británicos y se trasladaran a las ciudades. La destrucción de Londres era un alto precio que Churchill estaba dispuesto a pagar con el fin de procurar un alivio a su fuerza aérea y a los bombardeos a las bases en tierra. Los alemanes comenzaron a tener serios inconvenientes para responder a la defensiva inglesa y vieron caer a miles de sus aviones. Posteriormente, Hitler decide retirar sus aviones y cancelar la Operación León Marino e iniciar luego otra técnica para tomar control del territorio británico. 
Luego, en 1944, el Reino Unido participó en el Desembarco de Normandía en el que Ios Aliados pretendían invadir las costas y llegar al interior del continente. Tal desembarco se dio el 6 de junio de 1944 y los refuerzos alemanes que podrían haber empujado a los aliados hacia el mar vieron obstaculizada su labor debido a la abrumadora supremacía de los Aliados, quienes arruinaron las comunicaciones de los Potencias del Eje, detuvieron las provisiones por tren y atacaron las tropas que se dirigían a apoyar lo que sucedía en la costa. Sin embargo, la penetración que planeaban los Aliados al interior de Francia fue muy lenta ya que el territorio de Normandía favorecía la defensa de los soldados alemanes. A pesar de que los primeros acercamientos a la costa con paracaidistas fueran deficientes, los desembarcos en las playas fueron bastante eficaces, logrando llegar 16 kilómetros hacia el interior de territorio normando, lo que consolidó la victoria aliada ese día (Historia Siglo XX).

Era indudable que así como los Aliados no darían su brazo a torcer, los alemanes tampoco y por tal razón día a día trataban de mejorar sus artefactos con tecnología. Fue así como llegaron a la construcción del Cohete V2 que fue empleado en un ataque en contra de la ciudad de Londres en septiembre de 1944, en lo que se cree una represalia por las actuaciones británicas en Normandía. Este cohete era un misil balístico y fue el primero de largo alcance en crearse en el mundo, además de ser el primer elemento construido por el hombre en realizar un vuelo suborbital. ${ }^{2}$ Es justo en este punto donde inician

2 Un vuelo suborbital es el que se realiza a los 100 kilómetros o más. Es importante destacar en este punto que la comunidad internacional las actividades del hombre en el espacio ultraterrestre. Si bien la intención de los alemanes no era poner en órbita el cohete, sí se traspasó el límite del espacio aéreo. Añadiendo algunos detalles en relación con el origen de este Cohete V2, es curioso que Hitler en un principio no creía en la viabilidad del proyecto y era muy poco su apoyo económico con esta causa, ya que en su producción tuvieron lugar más de seis mil modificaciones y numerosos intentos fallidos. El primer sobrevuelo exitoso del proyecto del Cohete V2 se dio el 3 de octubre de 1942, en el Báltico y cayó en el punto que se había preestablecido. Es necesario destacar que este artefacto no tenía carga explosiva puesto que se trataba de solo un ensayo. Sin embargo, algo salió mal en el segundo ensayo, el 13 de julio de 1943, este cayó en cercanías suecas y sus autoridades rápidamente informaron a los británicos quienes recuperaron el cohete y analizaron sus partes esenciales; en razón de ello, se apresuraron a bombardear Peenemünde como estrategia de defensa contra aquel ingenio que se desplazaba a mil metros por segundo y que solo podía ser detectado por radares, segundos antes de la explosión. Es allí cuando Hitler se convence de que el V2 sí es algo trascendente, es decir, si los británicos se sintieron amenazados de tal manera que atacaron esta ciudad costera es porque el Cohete era un arma importante. Más adelante tiene lugar el ataque a los británicos en 1944 (Kolosimo, 1969). ${ }^{3}$ Para concluir esta

generalmente acepta que el límite entre el espacio aéreo y el espacio ultraterrestre se encuentra a los 100 kilómetros sobre la Tierra.

3 El creador de este artefacto fue Werner von Braun (1912-1977), científico alemán nacionalizado estadounidense quien al finalizar la guerra se trasladó a los Estados unidos, en 1945, donde fue director del 
parte del trabajo, es necesario señalar que la Segunda Guerra Mundial terminó con una victoria definitiva de los Aliados sobre el Eje en 1945, con gran parte de Europa totalmente destruida, con la creación de la Organización de las Naciones Unidas y con la chispa inicial que daría lugar a la Guerra Fría entre Estados Unidos y la Unión de Repúblicas Socialistas Soviéticas.

\section{La Guerra Fría: inicio de la carrera espacial}

La Unión Soviética luchó durante la Segunda Guerra Mundial y por tal razón se vio afectada significativamente, tanto así que perdió más de veintiséis millones de personas de su población total (Aracil, Oliver, \& Segura, 1998). Sin embargo, logró superar los obstáculos que la habían dejado en gran parte devastada y empezó a colaborar con los países del este de Europa que se habían visto perjudicados por la guerra. De esta manera, la Unión Soviética se instauró como una nación poderosa la cual gozaba del apoyo de muchos países que habían recibido beneficios de ella. Así, mientras ayudaba con la reconstrucción de Europa también forjaba su ideología, el comunismo, lo que alarmó a los Estados Unidos quienes mantenían una ideología capitalista. Sin embargo, aun en el inicio de la posguerra, los Estados Unidos y la Unión Soviética todavía realizaban actuaciones conjuntamente, ejemplo de ello fueron los Juicios de Núremberg en los que se juzgó y condenó a

programa de armas balísticas del ejército, participó en el desarrollo de varios cohetes e hizo importantes contribuciones que se utilizaron en el programa Apolo y permitieron a la humanidad alcanzar la Luna (Santillana, 2006). los líderes nazis por los crímenes perpetrados en contra de la humanidad.

Para 1946, la tensión entre los estadunidenses y rusos era más clara y en la Conferencia de Postdam, ${ }^{4}$ en la que se acordaría el futuro de Alemania, se confirmó lo sospechado: la alianza entre Estados Unidos y la Unión soviética era cada vez más débil. Es así que para el segundo mes de 1946 Joseph Stalin expresó en un discurso que el comunismo y el capitalismo eran absolutamente "incompatibles" y que la URSS debía prepararse para retomar las armas (Ocaña, 2003). Seguidamente, el gobierno soviético envió un documento a Washington en el que expresaba que la Unión Soviética era completamente hostil a occidente y que continuaría con sus políticas. Sumado a la evidente tensión entre estas dos naciones, el embajador ruso en Washington envió un telegrama a su gobierno en el que informaba de las presuntas intenciones que tenía Estados Unidos de controlar el mundo e iniciar un nuevo conflicto. Es para ese mismo año que las relaciones entre aliados se rompen definitivamente, la desconfianza crece entre naciones y los países occidentales están temerosos por la intención expansionista soviética. Los Estados Unidos no tardan en tomar medidas al respecto y es así que nace la Doctrina Truman, en la que los norteamericanos prometen ayuda a los gobiernos que se muestren en contra de la amenaza comunista. Además, los estadunidenses pusieron en marcha el Plan Marshall que

4 El principal tema fue la coyuntura de la Alemania vencida y su administración futura. Tomada la determinación de dividirla en cuatro zonas de ocupación, se estableció la existencia de un Consejo Supremo de Control compuesto por representantes de los territorios controlados por las potencias: Estados Unidos, Gran Bretaña, URSS y Francia. 
consistía en un programa en el que se llevaría a cabo una importante inyección de capital económico para la reconstrucción de Europa occidental. Si bien este nuevo programa instaurado traería consigo beneficios sustanciales a todos los habitantes del viejo continente, quienes tenían sus ciudades destruidas, también es cierto que dividió políticamente a Europa en dos: la occidental, que vio acelerada su recuperación gracias al Plan Marshall, y la oriental, los sometidos a la URSS que se negaban a aceptar ayuda proveniente de los Estados Unidos y por tanto su recuperación se daba a pasos lentos (Instituto de Tecnologías Educativas, 2010).

En la reunión que daba inicio oficialmente al Kominform, Andrei Jdanov, representante de la Unión Soviética manifestó lo que ahora conocemos como la Doctrina Jdanov, en la que implantó una visión del mundo dividido en dos bloques, e incentivó a los países a lo que él denominó el "campo antifascista y democrático" para que siguiera el liderazgo de Moscú. Paralelamente, siguiendo la misma línea de pensamiento de "división del mundo en dos partes", el 5 de marzo de 1946 el exprimer ministro británico Winston Churchill emitió una célebre conferencia en el salón de actos del Wetsminter College de la Universidad de Fulton en la cual advirtió al mundo de los pasos que daba el comunismo en Europa y anunciando con ello el inicio oficial de la Guerra Fría al manifestar que «desde Stettin, en el Báltico, hasta Trieste, en el Adriático, ha caído sobre el continente un telón de acero». Con esta afirmación, telón de acero o cortina de hierro, se refería a la frontera que había pasado de ser geográfica a ser ideológica que dividía el continente y separaba a los países que luego de la Segunda Guerra Mundial quedaron bajo la influencia de la Unión Soviética, de los países occidentales de ideología capitalista alineados con los Estados Unidos. De esta manera, la relación entre quienes fueran Aliados en la Segunda Guerra Mundial se desintegró totalmente(Bello Janeiro, 2006).

\section{Viajes fuera de la Tierra: la carrera espacial}

La rivalidad entre la Unión Soviética y los Estados Unidos era evidente, cada Estado solo esperaba el ataque del otro y la desconfianza estaba en el aire. Sin embargo, más allá del temor de que tuviera lugar una tercera guerra mundial había algo más que despertaba el interés de las naciones: la exploración del espacio ultraterrestre. Fue así que en el siglo XX el hombre logró dar los primeros pasos en la conquista del espacio (Santillana, 2006). Es así como lo que inició en ambos países con objetivos de defensa y ataque se direccionó rápidamente hacia la conquista del espacio y fue en el contexto de guerra que tuvo lugar la carrera espacial, como producto del conflicto. Tales sucesos merecen una observación más detallada.

\section{Primeros pasos en la carrera espacial}

\section{Octubre de 1957}

El 4 de octubre de 1957 los soviéticos lograron su primera hazaña, pusieron en órbita el Sputnik I y así consiguieron que los ojos del mundo se posaran en Moscú y en su gran proeza. El Sput- 
nik I era una esfera metálica de 58 centímetros de diámetro y de cuyo exterior sobresalían únicamente las antenas; orbitó la Tierra durante tres meses y completó 1400 revoluciones a la Tierra. ${ }^{5}$ A decir verdad, el Sputnik no cumplía una función trascendental ya que la tecnología desarrollada hasta el momento no había llegado tan lejos, así que dicho satélite solo emitía un pitido que podía captarse desde la superficie terrestre (Santillana, 2006). No obstante, la importancia de tal suceso no puede subestimarse ya que fue la primera vez que el hombre logró enviar un artefacto al espacio exterior.

\section{Noviembre de 1957}

Para noviembre del mismo año, en el que se envió el Sputnik I al espacio, la Unión Soviética anota su segundo punto, envía al espacio al Sputnik II, pero esta vez no se trataba de un satélite vacío, en esta ocasión el objetivo principal era enviar a un ser vivo al espacio con el fin de probar que era posible soportar la ausencia de gravedad y sobrevivir en órbita (Amiguet Molina, 2012). Este satélite estaba tripulado por una perra llamada Laika, reclutada en las calles de Moscú.

Diversas especies de animales fueron candidatas para este ensayo en el que se enviaría un organismo viviente al espacio. Así, se inició la búsqueda del animal que orbitaría la Tierra y fue así que se reclutaron varios canes de las calles de la capital soviética, debido a que los científicos e investigadores creyeron que un perro que

5 Su cohete lanzador fue el Semiorka. estuviera sometido normalmente a condiciones extremas soportaría con menor dificultad el experimento. Limitada la búsqueda, fueron preseleccionados tres canes, y una vez superadas las severas pruebas, Laika fue la escogida para ser la protagonista de este suceso histórico, sin embargo, su entrenamiento no terminaba allí, esta perra tuvo que someterse a muchas más pruebas, tal y como serían sometidos los seres humanos años más tarde. Laika viajaría en el interior de una cabina, sujeta a un arnés especial para lidiar con los efectos de la ingravidez y provista de unos dispensadores de agua y alimentos (Amiguet Molina, 2012).

La Agencia Espacial Soviética indicó que Laika regresaría a la Tierra en paracaídas. Sin embargo, tal información no era cierta puesto que tal cápsula no tenía un módulo de retorno así que se planeó la eutanasia de Laika por medio de alimento envenenado que se le suministraría. Fue así que pasaron más de 40 años para que se diera a conocer la verdad al mundo. En 2002, D. Maláshenco confesó que Laika había sobrevivido durante unas 5 o 7 horas; pero no fue el alimento adulterado lo que acabó con la vida de la perra, fue el estrés y el sobrecalentamiento de la cabina que alcanzó los $40^{\circ} \mathrm{C}$.

\section{Enero de 1958}

Los Estados Unidos tenían claro en este punto que estaban atrasados totalmente con respecto a la Unión Soviética, que se había anotado dos puntos con el lanzamiento del Sputnik 1 y el Sputnik 2. Por lo anterior se ven motivados a lanzar el primer satélite artificial norteamerica- 
no el 31 de Enero de 1958, el Explorer 1, y en cuya producción también tuvo que ver el científico alemán Werner von Braun. Este satélite pesaba alrededor de 15 kilogramos, en su interior contenía combustible, transmisores, instrumentos para medir las temperaturas, el impacto de meteoritos y una herramienta cuya función era medir la densidad de las moléculas atómicas en el espacio ultraterrestre. El 28 de febrero de ese mismo año el satélite cesó de transmitir, pero permaneció en órbita hasta marzo de 1970 (Vargas, 2007).

\section{Febrero de 1958}

La carrera espacial apenas iniciaba y por ahora los ganadores serían los soviéticos con un marcador de dos a uno, sin embargo, los norteamericanos debían procurar al menos un empate.

Fue así que el 5 de febrero de 1958, los Estados Unidos ponen en órbita un pequeño satélite que los soviéticos despectivamente asemejaron con una naranja. El Vanguard 1 llegó a órbita tras varios fracasos, pero ha sido el satélite con más tiempo en órbita de la Tierra. De alguna manera este satélite es un precursor de lo que conocemos actualmente como nanosatélites ya que pesaba unos 9,7 kilogramos en órbita, con un perigeo de 300 kilómetros. Los satélites Vanguard tenían un diseño elemental que consistía en una esfera de aleación de aluminio y magnesio revestidos de oro. El diámetro y peso variaban en cada misión. En el caso del Vanguard 1 el satélite tenía un diámetro de unos $16,5 \mathrm{~cm}$ y una masa de 1,47 kg. El peso de los otros satélites de la serie aumentó progresivamente: el
Vanguard 2 tenía una masa de 9,8 kg y el Vanguard 3 alcanzó los 45 kg.

Este satélite no pretendía romper ningún récord: con sus $16,5 \mathrm{~cm}$ de diámetro y sus $1,47 \mathrm{~kg}$ de masa el Vanguard 1 estaba equipado con 6 antenas de $30 \mathrm{~cm}$ de largo que emitían señales en $108 \mathrm{MHz}$ y $108.03 \mathrm{MHz}$ para telemetría e ingeniería. Dos sensores térmicos monitorearon durante 16 días la temperatura interna del satélite para comprobar el revestimiento térmico empleado. Como es evidente, el Vanguard 1 era un satélite experimental que se empleó para medir la densidad atmosférica a pesar de que esa no era su función. Estuvo activo hasta mayo de 1964, año en que su señal se dejó de emitir. En conjunto, entre diciembre de 1957 y el 18 de diciembre de 1958 se realizaron once tentativas de lanzamiento de satélites Vanguard, de los cuales solo tres fueron exitosos. No obstante y a pesar del difícil historial, el Vanguard 1 llevó a cabo una función muy importante en los avances de la tecnología espacial. En primer lugar, fue el primer satélite artificial equipado con paneles solares fotovoltaicos que producían energía eléctrica para sus materiales, comprobando la aptitud de esta tecnología. Desde tal momento, los satélites empezaron a emplear celdas solares fotovoltaicas. Los cálculos de la densidad atmosférica realizadas con el Vanguard 1 permitieron lograr conseguir una imagen más aproximada de la forma de la Tierra, y de alguna forma hace parte de los predecesores de los satélites geofísicos. Paralelamente, se mejoró la cartografía del océano pacífico y se obtuvieron medidas más precisas de la densidad de las capas superiores de la atmósfera (Vargas, 2007). 
Desde otro punto de vista el lanzador del Vanguard 1 probó la posibilidad de continuar con la tecnología de los cohetes de varias etapas y además permitió la creación de cohetes más grandes y potentes. Además, insertó en la tecnología espacial un sistema guiado de motor que se basó en articulaciones y no en las poco útiles aletas que hacían parte de los lanzadores militares. La idea de los creadores del Vanguard era que orbitara por unos dos mil años la Tierra, sin embargo, esto no sucedió así (Garcia Sagario, Zemiorka, 2012).

\section{Enero - septiembre de 1959}

La Unión Soviética no podía quedarse atrás de los Estados Unidos y nuevamente tomó la delantera en la exploración espacial. El 2 de enero de 1959 lanzó la primera sonda espacial que logró llegar a las cercanías de la Luna y conformó el primer resultado en el Programa Luna desarrollado por los rusos, se llamó Luna 1. Esta sonda era un artefacto con forma esférica de 80 centímetros de diámetro, fabricada con magnesio y aluminio. El propósito de esta sonda era estrellarse contra la Luna, sin embargo, debido a problemas técnicos esto no tuvo lugar. Esta sonda llevaba instrumentos de radio, dispositivos cuya función era estudiar el espacio ultraterrestre y otros equipos. Esta herramienta aportó nueva información desconocida hasta ese momento para el hombre. Además, detectó que la Luna no posee un campo magnético y que el viento solar que produce el sol atraviesa el Sistema Solar (National Aeronautics ans Space Administration, 2013). Era claro que los soviéticos iban ganando en esta competencia y no podían permitir alguna ventaja a los norteamericanos. Concretamente, el 12 de septiembre de 1959 la Unión Soviética lanzó la sonda Luna 2. Este artefacto tenía un diseño similar al del Luna 1, poseía la misma instrumentación, pero el Luna 2 era más liviano. Al igual que el primer modelo, esta sonda tomó un rumbo directo hacia la Luna, que duró 36 horas. El Luna 2 golpeó la Luna cerca de los 800 kilómetros del centro del disco visible el 13 de septiembre de 1959 (septiembre 14 a las 2:24 en Moscú) (Christy). Para ese momento histórico los norteamericanos habían lanzado los Pioneer 1, 2 y 3, los cuales faIlaron y no lograron llegar a la Luna.

\section{Octubre de 1959}

La humanidad contempla por primera vez la cara que se encontraba oculta de la Luna, todo gracias a las imágenes enviadas por la sonda soviética Luna 3, que fotografía el lado oscuro de Selene (Kolosimo, 1969). Tales imágenes fueron enviadas por medio de radio y requirieron un procesamiento complejo.

\section{Abril de 1961}

Los soviéticos llevan plenamente la delantera y ello no está en duda, pero para ratificar su triunfo parcial lanzan el Vostok 1, una nave que esta vez sorprendería aún más al mundo. Estaba tripulada por el cosmonauta ruso Yuri Gagarin. El Vostok 1 fue la primera nave que transportó a un ser humano en el espacio. Por cuenta de las preocupaciones a las reacciones adversas producidas por la falta de gravedad, los controles no estaban a cargo del cosmonauta sino de per- 
sonal en la Tierra, con el fin de procurar la seguridad del tripulante. La nave estaba conformada por una cabina esférica y antenas de radio externas, dentro de la cabina se encontraban un sistema de soporte de vida que monitoreaba al cosmonauta, instrumentación necesaria y un asiento de eyección. El módulo de servicio unido a la cabina llevaba combustible y cohetes de orientación, el cual se separó de la cabina en el reingreso a la Tierra (National Aeronautics and Space Administration, 2014). Después de orbitar la Tierra durante 89 minutos a una altitud de 315 kilómetros sobre el nivel terrestre, la nave entró nuevamente a la atmósfera y aterrizó en Kazajistán, 1 hora y 48 minutos después del lanzamiento. En esta misión espacial el cosmonauta expresó su frase célebre "La Tierra es azul» (Santillana, 2006). Este suceso en la carrera espacial reviste gran importancia puesto que fue la primera vez que una nave espacial llevaba a bordo a un ser humano y traspasaba los límites de la Tierra. Es importante señalar que no solo traspasaba los límites más allá de la Tierra, puesto que los estadounidenses quedaron estupefactos ante la hazaña soviética y enviaron sus felicitaciones auténticas a Moscú, lo que si bien no constituía el fin de la Guerra Fría, sí parecía ser un trato más amistoso entre potencias. Varios días después del regreso del Vostok 1 a la Tierra, Yuri Gagarin regresó a la capital soviética, desde donde inició una gira mundial, en la que todas las naciones que visitó lo recibieron cordialmente, lo cual fue realmente extraordinario porque tales visitas se produjeron en plena Guerra Fría. Gagarin no solo viajó entre el espacio y la Tierra sino también entre las dos partes en las que se dividía el mundo, el Este y el Oeste. De esta manera, las diferencias ideológicas se dejaron de lado transitoriamente para recibir al héroe que había visto la Tierra desde afuera y había regresado (Sanz, 2011).

\section{Mayo de 1961 y septiembre de 1962}

El 5 de mayo de 1961, tan solo unos días después de que Yuri Gagarin fuera lanzado al espacio, los norteamericanos enviaron a Alan Shepard en la nave Mercury Redstone 3, a realizar un vuelo suborbital, lo que los soviéticos consideraron vergonzoso y calificaron de "salto de pulgan. El vuelo solo duró 15 minutos, pero a diferencia de Yuri Gagarin, cuyo vuelo fue completamente automático, Shepard sí tuvo cierto control sobre su nave y por ello es considerado el primer astronauta estadounidense. Más tarde, Ios Estados Unidos lanzaron al espacio una cápsula, a la que bautizaron Friendship 7, la cual se consideró la primera nave norteamericana en ubicarse en la órbita terrestre, dirigida por el astronauta John Glenn (Vanguardia, 2011). Es importante destacar que el 12 de septiembre de 1962 el presidente de los Estados Unidos John F. Kennedy expresó en un discurso en la Universidad Rice que se comprometía con el país a emplear todos los esfuerzos necesarios para llevar a cabo la exploración espacial. De este discurso, se tiene el siguiente fragmento:

[...] Las promesas de esta nación solo se pueden cumplir si esta nación es la primera, y por lo tanto, pretendemos ser los primeros. En resumen, nuestro liderazgo en la ciencia y la industria, nuestras esperanzas de paz y seguridad, nuestras obligaciones para con nosotros 
mismos y los demás, nos obligan a hacer este esfuerzo para resolver estos misterios, para resolverlos por el bien de la humanidad y para convertirnos en la nación líder del mundo en el espacio [...]. Hemos decidido ir a la Luna. Elegimos ir a la Luna en esta década y hacer lo demás, no porque sean metas fáciles, sino porque son difíciles, porque ese desafío servirá para organizar y medir lo mejor de nuestras energías y habilidades, porque ese desafío es un desafío que estamos dispuestos a aceptar, uno que no queremos posponer, y uno que intentaremos ganar, al igual que los otros. Por estas razones considero que la decisión que tomamos el año pasado de acelerar nuestros esfuerzos en el espacio es una de las decisiones más importantes que se tomarán durante mi ejercicio del cargo en la Presidencia [...]. (Kennedy, 1962)

Podríamos decir que efectivamente el presidente Kennedy cumplió ampliamente su propósito, ya que los Estados Unidos fueron y actualmente son una potencia en la exploración espacial, tal y como se expondrá más adelante.

\section{De 1963 a 1966}

Durante estos tres años, la carrera espacial se vio enriquecida por múltiples hazañas de los soviéticos y de los norteamericanos. Ejemplo de ello fueron los lanzamientos del Vostok 5 , tripulado por Valentina Tereshkova, la primera mujer cosmonauta. Por su parte, El Ranger 6 y el Ranger 7 fueron lanzados en 1964 por los estadounidenses, y un año después, en 1965, se lanzaron el Ranger 8, el Luna 9 y el Zond 3, que fotografió una zona de cerca de cinco millones de kilómetros cuadrados de la cara lunar no visible desde la Tierra, lo que dio una imagen completa de tal hemisferio del satélite natural. Es fundamental resaltar que en este período también tuvo lugar una de las más importantes hazañas en la carrera espacial: la primera actividad extravehicular llevada a cabo por un hombre. El 18 de marzo de 1965 el cosmonauta ruso Alexei Leonov se convirtió en el primer ser humano en pasear por el espacio, estuvo doce minutos y nueve segundos fuera del Voskshod 2 , sujeto únicamente por medio de una correa de sujeción de 5,35 metros. Cuando el cosmonauta se dispuso a regresar a la nave, el traje que estaba usando se infló en el vacío del espacio, impidiéndole retornar normalmente al Voskshod 2. Por lo tanto, tuvo que abrir una válvula que poseía su traje para liberar el aire y poder ingresar nuevamente a la nave (Starmus, 2014) (Novosti, 2010).

Luego, el 31 de marzo de 1966, partía de la Tierra el vehículo soviético Luna 10, que orbitó alrededor de la Luna y recogió datos indispensables para la gestación de la incursión lunar (Kolosimo, 1969).

\section{Destino: la Luna}

Los esfuerzos por acercarse al astro más cercano a la Tierra eran notorios y, contrario a lo que podría creerse, el impacto de la nave de propiedad soviética Luna 1 en la superficie de nuestro satélite natural no fue un experimento fallido, fue la más clara demostración de que era perfectamente posible lanzar un artefacto con destino a la Luna. Desde ese momento, ambas potencias compitieron por alcanzar logros en la 
carrera espacial que ya había iniciado. Fue así que los soviéticos continuaron con el programa lunar. No obstante, en el lapso temporal en el que la Unión Soviética envió el Luna 3, que remitió las primeras fotos del satélite en 1959, y el Luna 4, en 1959, los norteamericanos enviaron a la Luna sondas del programa Ranger, los cuales también lograron llegar al satélite e impactar contra él. Para ese momento ya era claro que ambas naciones tenían la capacidad de llegar a la Luna. Sin embargo, todavía no se habían alcanzado dos logros fundamentales. El primero de ellos, conseguir descender pacíficamente sobre la superficie lunar sin estrellarse, especialmente si se planea la posibilidad de enviar una nave tripulada al astro celestre. El segundo, la capacidad de regresar a la Tierra de manera segura (Santillana, 2006).

\section{El primer alunizaje}

La Unión Soviética y los Estados Unidos se propusieron conseguir dirigir naves hacia la Luna sin que estas impactaran catastróficamente en el astro celeste. Se crearon dos sondas que lograron tal propósito.

En enero de 1966, la sonda soviética Luna 9 consiguió aterrizar suavemente sobre la superficie lunar y enviar fotografías a la Tierra. Era una máquina relativamente liviana, pesaba 99 kilogramos. Además, tenía en su interior sistemas para controlar la temperatura y una cámara para poder captar las imágenes. El Luna 9 arribó a la superficie del satélite natural el 3 de febrero de 1966, y seguido de tal exitoso aterrizaje unas antenas se desplegaron y se posicio- naron para retransmitir información a la Tierra. La cámara con la que venía el Luna 9 contaba con un sistema de espejo que podría orientarse, con el fin de tener una visión más amplia de la superficie del astro gracias a sus giros. Fue así como la sonda empezó a los cinco minutos la misión de plasmar el ambiente durante siete sesiones de radio, con un total de ocho horas y cinco minutos de duración, que fueron emitidas a la Tierra en tres series de imágenes de televisión. La primera imagen tardó siete horas en llegar, con un total de nueve imágenes adquiridas en cinco panoramas. Cuando fueron ensambladas permitieron examinar el panorama alrededor de Luna 9, que comprendía incluso las rocas y el horizonte hasta unos 1,4 kilómetros de distancia. De esta manera fue que los soviéticos obtuvieron la primera llegada de imágenes desde una superficie externa a la Tierra (Sondas espaciales, 2011).

Gracias a las imágenes que captó la cámara de la sonda, se obtuvo información relacionada con las características de la superficie lunar, más específicamente respecto de la cantidad y distribución de los cráteres. Del mismo modo, es probable que el descubrimiento más importante que se hizo en tal misión fuera el lograr comprobar la dureza del suelo lunar, es decir, que la Luna pudiera soportar en su superficie un objeto sin que este se hundiera. Este artefacto fue el primero producido por el equipo de diseño de Lavochkin, que desde ese momento en adelante se encargaría de fabricar todas las sondas lunares e interplanetarias soviéticas y rusas (Sondas espaciales, 2011). 
Cinco meses más tarde, los norteamericanos enviaron la sonda Surveyor 1, que logró el primer aterrizaje suave en la superficie lunar. Esta misión fue considerada un éxito total. Los principales propósitos del programa Surveyor fueron una serie de vuelos robóticos dirigidos hacia la Luna, con el fin de que tuvieran un aterrizaje exitoso para poder apoyar los arribos del programa Apolo, y lograr además el desarrollo y la validación de la tecnología necesaria para el aterrizaje suave en la Luna, el suministro de datos sobre la compatibilidad de la estructura del Apolo, con las condiciones observadas en el suelo lunar, y la incrementación de la información concerniente a la Luna.

\section{Planes de una misión tripulada a la Luna}

Casi al mismo tiempo del éxito producido por la primera sonda del proyecto Surveyor, la agencia espacial estadunidense puso en marcha el programa Lunar Orbiter, que conformó una serie de naves cuyo propósito era llegar a la órbita lunar, pero no alunizar. Su principal función era la de realizar sobrevuelos sobre la superficie de la Luna, con el fin de llevar a cabo una tarea de reconocimiento y poder escoger un lugar apropiado para el alunizaje de las distintas misiones que vendrían más adelante. Las sondas del proyecto Lunar Orbiter lograron captar el 99\% de la superficie del astro en imágenes de hasta sesenta metros.

La sonda Lunar Orbiter 1 tomó la primera imagen de la Tierra observada desde la Luna. Esta fue transmitida el 23 de agosto de 1966 a la estación espacial de Madrid en España y obtuvo más de doscientas fotografías. Este objeto espacial se estrelló contra la Luna el 29 de octubre de 1966, pero fue de gran ayuda para lograr eficazmente la recolección de información. El Lunar Orbiter 2 se lanzó el 6 de noviembre de 1966 y finalizó su funcionamiento el 11 de octubre de 1967, luego de haber tomado más de 422 fotografías de la Luna. Por su parte, el Lunar Orbiter 3 se lanzó el 5 de febrero de 1967 e impactó contra la Luna el 9 de octubre de 1967 y, al igual que las sondas anteriores pertenecientes al mismo proyecto, envió más de cuatrocientas fotografías de la Luna. El Lunar Orbiter 4 se lanzó el 4 de mayo de 1967, tomó 163 fotografías y luego se estrelló contra la superficie lunar el 6 de octubre de 1967. Del mismo modo, el Lunar Orbiter 5 se lanzó el 1 de agosto de 1967 y finalizó su misión el 31 de enero de 1968. Esta sonda logró captar aún más información que las anteriores, puesto que completó la representación cartográfica de la Luna en un 99.5\%. Además, envió 212 imágenes de la Luna de media y alta resolución y, sumado a ello, documentó 36 zonas de interés, cinco de descenso para las misiones Apolo y toda la cara oculta del satélite natural. Para resumir, las tres primeras sondas del programa Lunar Orbiter cumplieron únicamente la función de recopilar información y hacer reconocimiento fotográfico de la Luna, las otras dos sondas completaron casi al máximo este reconocimiento (Santillana, 2006).

No obstante, Ios soviéticos no se quedaron atrás y pusieron en marcha su programa Zond, del cual es destacable su sonda Zond 5, la primera herramienta de esta categoría que Ilega a la Luna y retorna a la Tierra sin estrellarse contra 
nuestro satélite natural. Es por tal motivo que es considerada la precursora de los viajes a la Luna tripulados (CTV). Es así que poco a poco se iba preparando el ambiente para lanzar al espacio la primera misión con tripulación a bordo. ¿Serán los soviéticos o los norteamericanos los primeros en llegar a la Luna? La historia ya dio respuesta a este interrogante.

\section{El programa Gemini}

Pocas semanas después de que el astronauta Alan Shepard se convirtiera en el primer hombre norteamericano en salir al espacio ultraterrestre, el entonces presidente, John F. Kennedy, manifestó que los planes estarían encaminados a enviar astronautas a la Luna antes de que finalizara la década. Con base en el programa Mercury y sus aciertos, que incluían el diseño de la cápsula, la NASA empezó a diseñar una nave que pudiera llevar dos tripulantes, y que serviría después para los programas Apolo. Este proyecto tenía como objetivo "desarrollar una mayor capacidad operacional en el espacio, investigando también los problemas de trabajar y vivir en él». Podría afirmarse que el proyecto Gemini fue un éxito en cuanto se dieron diez vuelos entre marzo de 1965 y noviembre de 1966, y además tuvo lugar la primera caminata espacial. EI astronauta Ed White fue el primer hombre en realizar una caminata extravehicular, actividad que duró aproximadamente 22 minutos y que luego fue superada por el astronauta Buzz Aldrin, quien caminó durante más tiempo durante el final de la misión Gemini (Discovery, 2014).
«Houston, aquí Base Tranquilidad, el Águila ha alunizado»

El 21 de julio de 1969, el planeta entero tenía puestos los ojos sobre las transmisiones por televisión que se hacían de dos astronautas caminando sobre la Luna, quienes, además, contemplaban el amanecer terrestre desde el satélite natural. De esta manera, tres norteamericanos, Neil Armstrong, Buzz Aldrin y Michael Collins subieron a una nave espacial, el Apolo $11,{ }^{6}$ situada en el extremo norte de Cabo Kennedy e impulsada por el cohete Saturno, que los pondría fuera de la Tierra y de esta manera empezarían a orbitar la Luna.

En el vuelo del Apolo, el control estuvo a cargo de los tres hombres que conformaban la tripulación, es decir, de manera semejante a como sucede en un avión. Si bien el centro de mando autorizó el despegue y suministró informes de posición de radar y de otros tipos, la tripulación del Apolo gozó de autonomía absoluta. No obstante, la cápsula lunar tuvo un sistema automático que no permitió que se dieran fallas que pudieran desencadenar en una tragedia. La cavidad en la que se encontraban los astronautas tenía forma cónica, de cuatro a 4,5 metros de diámetro en la base, y una longitud de 3.6 metros, y contenía alimento, equipo científico, instalación sanitaria, agua, oxígeno y demás suministros. De tal manera, y con todo lo necesario, el módulo lunar se posó sobre la Luna.

6 También lo llamaban "el águila”. 
Neil Armstrong y Buzz Aldrin se ubicaron en el Módulo Lunar una vez completada la decimotercera órbita alrededor del cuerpo celeste, y con las comunicaciones con la base en Tierra interrumpidas, los astronautas se dispusieron a llevar a cabo una maniobra, con el fin de dejar de girar en torno a la Luna y descender suavemente a la superficie. Fue así que sucedió: Ilegaron al lugar que fue previsto para el aterrizaje sin ningún contratiempo.

Todo al interior de la cápsula funcionaba normalmente, y se puso en modo automático la nave. El 20 de julio de 1969, a las 15:17 de Houston, la nave estaba quieta sobre la superficie lunar. Acto seguido, Neil Armstrong descendió de la cápsula, pidió autorización a Houston y dio un pequeño salto en el que pisa suelo lunar. Alí es cuando pronuncia su frase célebre: "Un pequeño paso para un hombre, un gran salto para la humanidad». El tercer astronauta, Michael Collins, continuó en órbita lunar al comando del módulo de mando Columbia, que abordaron nuevamente Armstrong y Aldrin 21 horas más tarde para retornar a la Tierra (Paralibros.com). Todo marchaba según lo planeado, excepto por la sonda soviética Luna 15, que orbitaba la Luna y podía interferir con la órbita del Apolo. Sin embargo, eso no sucedió. La misión duró varias horas y en ese tiempo los astronautas tomaron algunas fotos, recolectaron varias muestras del suelo lunar, dejaron mensajes y saludos de todas las naciones del mundo, las medallas recibidas por las familias de Yuri Gagarin y Vladimir Komarov, y las insignias de los fallecidos en el Apolo 1. Enseguida, Armstrong y Aldrin desplegaron la bandera estadounidense y la enclavaron en el suelo satelital. El alunizaje tuvo lugar y los astronautas se dispusieron a regresar a la nave, con el fin de volver a la Tierra. Pero, antes de ello, instalaron a algunos metros del módulo lunar un sismómetro para poder detectar la actividad sísmica selenita y un retro reflector de rayos láser, con el propósito de hacer una medición precisa de la distancia que hay de la Tierra a nuestro satélite (Sarkissian).

En el viaje de regreso, el material aislante del que está fabricada la cápsula Apolo no permitió que al entrar en la atmósfera terrestre la nave ardiera como un meteoro, puesto que viajaría a una velocidad que sería superior a los 27.000 kilómetros por hora. La nave descendió en Tierra, y para ello tuvo dos paracaídas en la última fase del descenso, además de un paracaídas más pequeño que disminuyó la velocidad (Holmes, 1966). Finalmente y como se tenía planeado desde un principio, la nave tuvo su amerizaje en el océano pacífico el 24 de julio de 1969 (Santillana, 2006).

\section{La última visita}

Los últimos astronautas que han visitado la superficie lunar son los tripulantes de la misión Apolo 17, quienes pisaron la Luna en 1972. Con tres tripulantes, la misión Apolo 17 fue lanzada al espacio el 7 de diciembre de 1972 a bordo de un cohete Saturno, que siempre había sido el vehículo propulsor del proyecto Apolo. La misión transcurrió con toda normalidad, y no se presentaron incidentes. El único percance que tuvo lugar fue un retraso de casi tres horas, debido a un error en el control de presurización de la ter- 
cera fase del cohete. Por cuenta de ello, el Apolo 17 fue el primer objeto espacial que tuvo su lanzamiento en horas de la noche. Los tripulantes de la cápsula eran Eugene A. Ceran, Harrison H. Schmitt y Ronald E. Evans. Al módulo lunar también le llamaron Challenger, y al módulo de mando se le denominó América.

La cápsula aterrizó sin ningún inconveniente, así que los astronautas se dispusieron a realizar sus labores de recolección e instalación de equipos científicos similares a los que se instalaron en la misión Apolo 11, como un aparato para medir la velocidad, la frecuencia y la masa con que caen los meteoritos en la superficie lunar y los efectos que estos impactos producen en el suelo, un gravímetro de superficie para estudiar la atracción que la Tierra y el Sol ejercen sobre la Luna, una herramienta para identificar el perfil sísmico del suelo lunar, un medidor de la composición química de la atmósfera lunar, un artefacto para recolectar información que permita conocer si hay agua bajo la superficie de la Luna, entre otros aparatos que medirían frecuencia y energía en la Luna. En resumen, la misión Apolo 17 batió varios récords, como la estancia más larga en la superficie lunar, con casi 75 horas, máximo tiempo de exploración, con casi 22 horas, y el período más largo sin interrupciones en la superficie lunar (Ferreira Lorenzo, 2012). Luego de obtener la información necesaria, los astronautas se dispusieron a regresar a Tierra, pero antes de hacerlo dejaron una placa con la siguiente inscripción: "Aquí el hombre completó su primera misión en la Luna. Diciembre 1972. Ojalá que el espíritu de paz en el que llegamos sea reflejado en las vidas de toda la humanidad" (Santillana, 2006). El gran costo de las misiones espaciales tripuladas dirigidas hacia la Luna provocó que la NASA suspendiera por un tiempo estas actividades, y más bien prestara atención a naves no tripuladas.

\section{Sondas hacia otros mundos}

\section{Rumbo a Marte}

La Luna nunca fue el único objetivo para los soviéticos ni para los norteamericanos, había más cuerpos celestes por los que la humanidad sentía curiosidad, como el planeta rojo. De esta manera, los primeros intentos por llegar a pisar suelo marciano se llevaron a cabo por la Unión Soviética en octubre de 1960, con dos sondas del programa Marsnik. No obstantes, solo fue hasta 1963 que una sonda de origen ruso orbitaría Marte. La Mars 1 giró alrededor del planeta rojo por unos días, y luego la base central en Tierra perdió contacto con ella. Si bien los norteamericanos lograron llegar a la Luna y viajar múltiples veces, los soviéticos no habían desaparecido de la competencia, por lo que los Estados Unidos enviaron en 1965 la sonda Mariner 4, que fue la primera en conseguir llegar a Marte luego de un vuelo de casi ocho meses, y fue además la primera en tomar fotografías de la superficie de este planeta.

Las expediciones a Marte apenas iniciaban. Como evidencia de ello, en 1971 los soviéticos lanzaron la sonda Mars 2. Esta vez, gracias a la corrección de algunos errores que se produjeron en la primera sonda enviada, logró orbitar el planeta rojo. La Unión Soviética no se quedaría 
atrás, y para finales del mismo año enviaron la sonda Mars 3, que se creía sería un éxito total al tocar suavemente la superficie marciana. Sin embargo, decepcionó a todos cuando perdió comunicación con tierra instantes más tarde de haber llegado al suelo del planeta rojo.

Los soviéticos habían tomado de nuevo la delantera en la competencia. Por lo tanto, el 19 de julio de 1976 los norteamericanos Ianzaron al espacio la sonda Viking 1 (Libertad Digital, 2010), seguida casi inmediatamente por la Viking 2. Ambos objetos constituyeron un total orgullo para la nación norteamericana, ya que ambos artefactos lograron tomar y enviar imágenes a la Tierra. Tales artefactos se encontraban equipados con dispositivos que permitirían realizar análisis de temperatura y composición al suelo marciano. Luego de esta última misión, la exploración en Marte se detuvo por casi dos décadas. Fue hasta 1992 que continuaron las misiones a Marte, lideradas por la NASA, con el lanzamiento del Mars Observer, cuyo propósito era entrar en órbita de Marte. Sin embargo, la comunicación con la sonda se perdió. Solo fue hasta 1997, con la puesta en órbita marciana de las sondas Mars Global surveyor y del Mars Pathfinder que se logró observar, por medio de imágenes trasmitidas por las sondas desde la superficie del planeta rojo, el característico desierto rocoso que conforma la capa externa del suelo de Marte (National Aeronautics and Space Administration, 2012).

\section{Exploración a los gigantes}

\section{Las sondas Pioneer y Voyager}

Las sondas Pioneer y Voyager fueron las primeras en llegar a los planetas gaseosos. ${ }^{7}$ Se desplazaron hacia ellos y tomaron registros fotográficos que fueron enviados a la Tierra. La sonda Pioneer 10 se lanzó el 2 de marzo de 1972, por medio de un cohete propulsor particularmente potente, que logró impulsarla a más de 51.000 $\mathrm{km} / \mathrm{h}$, de manera que ya había dejado atrás la Luna y Marte, en tan solo doce semanas. Luego de conseguir atravesar el cinturón de asteroides, llegó a júpiter a finales de 1973. Se acercó aproximadamente a unos 130.000 kilómetros del quinto planeta del Sistema Solar, y tomó y envió fotografías. La Pioneer 10 poseía una placa, cuyo objetivo era aportar algo de información sobre la misión y la humanidad a las posibles civilizaciones extraterrestres que pudieran encontrarse con la sonda (Santillana, 2006). Por lo tanto, se puede decir que este objeto espacial es el mensajero del primer intento de comunicarse con seres del universo. Así pues, la sonda continuó su viaje hacia el Sistema Solar exterior, y mantuvo contacto con la Tierra hasta 2002. Un año después se perdió completamente su débil señal.

El programa Pioneer trajo consigo el lanzamiento de más sondas al espacio, como la sonda

7 Los planetas ligeros o gigantes se localizan en la parte externa del Sistema Solar. Son planetas constituidos básicamente por hidrógeno y helio, reflejo de la composición de la nebulosa solar primigenia. Tienen importantes actividades meteorológicas y procesos de tipo gravitacional, con un pequeño núcleo y una gran masa de gas en convección permanente. 
hermana de la Pioneer 10, la Pioneer 11, que fue lanzada a principios de 1973, y cuyo objetivo era el planeta gaseoso Saturno. Del mismo modo, alcanzó Júpiter en diciembre de 1974 y logró conseguir imágenes impresionantes de la Gran Mancha Roja, la que se cree que es una tormenta gigante que gira en la atmósfera de Júpiter. Se asemeja a un huracán en Tierra, pero el diámetro de tal fenómeno es más de dos veces el tamaño de la Tierra. Los vientos interiores de esta tormenta alcanzan velocidades de alrededor de 270 millas por hora. Hasta el momento no se ha logrado determinar con certeza por qué el color rojizo y el momento de su aparición, pero ha sido vista en Júpiter desde que la gente comenzó a observar por medio de telescopios, hace aproximadamente 400 años (Hermans Killam). Así, tras un viaje de casi cinco años, la Pioneer 11 se acercó a Saturno y obtuvo las primeras imágenes del planeta.

La Pioneer 11 posibilitó conseguir importantes datos sobre el planeta de los anillos y su enorme luna, Titán. Gracias a la toma de tales imágenes, los científicos en la Tierra lograron descubrir que Saturno poseía dos nuevos satélites y un nuevo anillo. Después de este importante encuentro con el sexto planeta del Sistema Solar, la sonda continuó su viaje hacia las zonas exteriores del Sistema Solar. La última señal percibida por la Tierra de la Pioneer 11 se dio en 2005.

Varias décadas después del lanzamiento de las sondas Pioneer, se enviaron al espacio ultraterrestre las dos sondas Voyager. Fue en enero de 2005 que los Estados Unidos lanzaron al es- pacio las naves espaciales que más lejos han llegado, puesto que sobrepasaron los diez mil días de operación.

Las dos sondas Voyager fueron enviadas al espacio en 1977. El 20 de agosto partió la Voyager 1, y el 5 de septiembre la Voyager 2. Respecto de la sonda Voyager 1, la NASA anunciaba el 25 de agosto de 2012 que, por primera vez en la historia de la exploración espacial, una nave construida por el hombre había logrado salir del Sistema Solar para adentrarse en el espacio interestelar. El hecho histórico no se anunció antes, puesto que los científicos de la agencia espacial norteamericana necesitaban estar seguros de los datos antes de darlos a conocer al mundo. Actualmente, la Voyager 1, lanzada varias décadas atrás, se encuentra aproximadamente a unos 18.200 millones de kilómetros de distancia, y se sigue alejando de la Tierra cada año, a una velocidad de 17 kilómetros por segundo. Esta característica convierte a la Voyager 1 en una de las naves más veloces nunca lanzadas al espacio. Es importante aclarar que esta velocidad no es gracias a la acción directa de los vehículos propulsores, sino al impulso que, tras de casi cuarenta años de viaje, ha ido adquiriendo a su paso por varios planetas de nuestro Sistema Solar.

Se estima que se recibirá señal en la Tierra de la Voyager 1 hasta el año 2025, justo en el momento en que sus generadores de plutonio se agoten completamente. Luego, sin un destino fijo y sin manera de controlarla, la nave continuará su viaje a través del espacio sin que jamás volvamos a saber nada de ella. A pesar de que 
la sonda recorra más distancia que cualquier otra nave jamás fabricada por el hombres, y de haber logrado, por tal razón, un hito histórico, es pertinente reconocer que en términos de la inmensidad del universo, la Voyager 1 apenas se ha alejado un poco de la Tierra. Es suficiente con recordar que la estrella más próxima al Sol, Alfa Centauro, está ubicada a cuatro años luz de distancia, que el centro de la Vía Láctea está a 26.000 años luz y que Andrómeda, la galaxia más cercana a la nuestra, se encuentra a dos millones de años luz. En comparación con tales datos, los más de 18.000 millones de kilómetros recorridos por la Voyager 1 escasamente suponen 16,2 horas luz (Nieves, 2013).

Por su parte, la Voyager 2 llegó a Júpiter en julio de 1979 y al planeta de los anillos en agosto de 1982. En ese momento se consideró totalmente necesario lograr mejorar las antenas que recibían la información de las sondas, con el propósito de poder seguirlas en su viaje a tan largas distancias. Cuatro años después, la segunda sonda del programa Voyager se volvió la primera nave construida por el hombre que visitó Urano. Para mediados de 1986 llegó al tercer planeta gaseoso, y comenzó a tomar imágenes e información para ser enviadas a los científicos en la Tierra. Tres años después, logró alcanzar Neptuno y luego salió del Sistema Solar (SantiIlana, 2006).

Es necesario resaltar la labor de un hombre que participó de manera significativa en las operaciones Mariner, Viking, Voyager y Galileo, el astrofísico estadounidense Carl Sagan, quien pensó la idea de enviar información por medio de las placas de las sondas a otras civilizaciones extraterrestres, con datos sobre la Tierra, como grabaciones sonoras e imágenes. Sus investigaciones y descubrimientos más importantes se centraron específicamente en los planetas de nuestro Sistema Solar. Fue uno de los primeros astrofísicos en entrever que Europa, un satélite de Júpiter, podía tener un océano bajo una capa de hielo externa. Además, estudió la atmósfera venusina, los cambios estacionales marcianos, y la luna de Saturno, Titán (Santillana, 2006).

\section{Transbordadores espaciales}

Hasta el momento se ha hablado acerca de objetos espaciales relativamente pequeños, que están diseñados para realizar su misión al espacio y, probablemente, no regresar a la Tierra. Pero, para la viabilidad del programa espacial era imprescindible desarrollar naves reutilizables. Uno de los problemas fundamentales de la exploración espacial es el elevado costo de las misiones. Es necesario recordar que hasta hace poco los cohetes no eran reutilizables. Para cada lanzamiento se utilizaba un cohete que se separaba por etapas y se perdía a medida que se quemaba el combustible. Por tal razón, se consideró importante crear un vehículo espacial que pudiera usarse más de una vez y no se destruyera en cada misión. Este vehículo fue el transbordador espacial de la NASA.

En el momento del lanzamiento, el transbordador tenía adheridos unos cohetes propulsores que se desprendieron durante las primeras etapas del lanzamiento y cayeron al mar, de donde se recobraron para emplearse nuevamente en 
lanzamientos futuros. Una vez se desprendieron de los cohetes propulsores, el vehículo se impulsó por sus propios medios, hasta entrar en órbita alrededor de la Tierra. Luego de orbitar alrededor de nuestro planeta, el transbordador volvió a aterrizar como un avión normal, a una velocidad de unos $300 \mathrm{~km} / \mathrm{h}$.

Del programa espacial norteamericano se pueden destacar varios transbordadores. El primero es el Enterprise. Este transbordador prototipo fue llamado así por la nave Enterprise, de la popular serie de televisión Viaje a las Estrellas. En 1977, dos pilotos Ilevaron a cabo el primero de cuatro vuelos experimentales a siete mil metros de altura. Para 1979, al Enterprise se le adhirió un tanque de combustible y propulsores. Sin embargo, el transbordador nunca llegó a despegar, debido a que ya se había completado la construcción del Columbia. Este transbordador pesó 71 toneladas y fue modificado unas 150 veces, hizo su vuelo inaugural en 1981, fue reacondicionado entre 1999 y 2002, y lanzado de nuevo el 1 de marzo de 2002. El 1 de febrero de 2003 se destruyó mientras ingresaba nuevamente a la atmósfera terrestre; se cree que tal desastre fue ocasionado por una falla en el escudo termal de la nave. Es considerado, además, el transbordador más viejo.

El transbordador Challenger fue la segunda nave en entrar en operación y completó su primer vuelo en 1983. Durante las diez misiones en las que participó la nave estuvo en el espacio por un total de 69 días y orbitó la Tierra 987 veces. En una de sus misiones, el astronauta Bruce McCandless abandonó el transbordador sin un cordón de seguridad y efectuó una caminata espacial de treinta metros; fue el primer astronauta en realizar una actuación tan arriesgada. Posteriormente, en enero de 1986 el transbordador challenger explotó 73 segundos antes de despegar, y por cuenta de ello sus siete tripulantes fallecieron.

El transbordador Discovery fue la tercera nave espacial en este orden de transbordadores. A pesar de que el Discovery fue construido como el Challenger, permitiéndole llevar en el compartimiento de carga un cohete auxiliar, Centauro, pesó aproximadamente tres toneladas menos que el Columbia. Sin embargo, debido a la tragedia del Challenger, que costó varias vidas, el programa se suspendió por considerarse muy riesgoso.

Por su parte, el transbordador Atlantis fue el cuarto transbordador puesto en funcionamiento, tenía un peso de 77 toneladas y llevó misiones como el Explorador Planetario Galileo, en 1989. Algunos años después, se dio a conocer el transbordador Endeavour, cuya primera misión se dio en mayo de 1992 y su propósito era el de rescatar a un satélite de telecomunicaciones que había salido de control. Sorprendentemente, el Endeavour pudo permanecer en el espacio hasta por 28 días (Discovery Channel).

Hasta el momento los únicos transbordadores espaciales que se encuentran en funcionamiento han sido fabricados por los Estados Unidos. Pero como se ha visto, los soviéticos no se han quedado atrás y han fabricado sus propios prototipos. Fue así que la agencia espacial soviéti- 
ca construyó en los años ochenta un transbordador espacial denominado Buran.

En 1976, los altos mandos soviéticos se mostraron preocupados por la presentación oficial del primer transbordador norteamericano, y por cuenta de ello emprendieron un programa paralelo y se dotaron de un transbordador espacial propio. El 12 de abril de 1981 tuvo lugar el primer vuelo del columbia, lo que intranquilizó a los soviéticos, pues pensaban que los transbordadores se emplearían con fines militares. Con este ambiente de tensión, los estrategas de Moscú se enfrentaban a la necesidad de disponer de un vehículo espacial de capacidades iguales a las de los transbordadores, y responder al shuttle threat. Así nació el programa de producción de vehículos espaciales tripulados y reutilizables (Zak, 2014).

Seguidamente, los científicos e ingenieros soviéticos focalizaron sus esfuerzos en desarrollar un cohete con capacidades superiores, para poder transportar con seguridad al espacio una nave espacial muy pesada, y ser totalmente reutilizable. Mientras tanto, Estados Unidos utilizaba combustible sólido para impulsar durante el despegue y un enorme tanque de combustible líquido para alimentar los motores del transbordador. Los rusos utilizaron solo combustible líquido, y la nave soviética sería transportada al espacio como una carga más por el cohete.

Sin embargo, la producción del transbordador Burán no estuvo exenta de obstáculos, tal y como ha sucedido con todos los artefactos que se pretendían lanzar al espacio. Fue así que,

mientras los ingenieros rusos consideraban más pertinente emplear una pequeña nave ligera, con menos tripulación, los altos mandos ordenaron que debía ser en todos los sentidos semejante al transbordador norteamericano. El primer Burán fue terminado en 1984.

Curiosamente, se construyó un vehículo de pruebas mucho más eficiente que el utilizado por el programa estadounidense. La nave soviética, a pesar de tratar de ser una copia del transbordador norteamericano, tuvo significativas diferencias con su símil, especialmente por los motores más pequeños que permitían más espacio para el transporte de carga y por su más sencilla maniobrabilidad en la atmósfera.

El Burán despegó el 15 de noviembre de 1988 en un viaje no tripulado desde Baiknur. La nave realizó dos órbitas antes de volver a entrar a la atmósfera. El aterrizaje fue totalmente automático, sin intervención humana, y con una precisión destacable. A pesar del exitoso primer viaje del Burán, no tuvieron lugar más misiones, debido a la compleja situación económica y política que vivía la URSS.

Paralelamente, la agencia espacial europea fabricó su propio transbordador, el Hermes. Sin embargo, nuevamente los problemas económicos fueron motivo para suspender el proyecto a mediados de la década de los noventa (Bowen, 2013). 


\section{Vivir más allá de la Tierra}

\section{Primeras instalaciones espaciales}

Entre 1971 y 1982 la agencia espacial soviética ubicó en órbita terrestre siete estaciones espaciales de la serie Salyut. Eran artefactos relativamente sencillos, conformados por un solo módulo y tripulados por cortos períodos de tiempo. En abril de 1971, los soviéticos lanzaron y pusieron en órbita la estación Salyut 1, la primera estación espacial digna de tal nombre, con capacidad de alcanzar la órbita terrestre, automáticamente, sin la exigencia de tripulación y con posibilidad de ser habitada por seres humanos por ciertos períodos de tiempo, así como recibir naves tripuladas Soyuz mediante un puerto de atraque. Hasta ese momento, los registros de permanencia de vida fuera de la Tierra habían tenido lugar únicamente dentro de las cápsulas espaciales como el Apolo.

La estación Salyut 1 constituyó uno de los más importantes avances en la exploración espacial. Sin embargo, como se ha visto, la carrera del hombre por llegar al espacio ha estado llena de dificultades y tragedias.

Los primeros tripulantes del Salyut 1, Georgi Dobrovolski, Vladislav Vólkov y Viktor Patsayev, luego de cumplir con su misión en el espacio y tras haber permanecido 23 días habitando en la estación, aterrizaron suavemente a bordo de la nave Soyuz 11, pero debido a un escape en la válvula del módulo de descenso se provocó la despresurización de la nave y el fallecimiento de la tripulación.
Luego del trágico desenlace de los cosmonautas, se vio perjudicado el éxito de los avances, lo que ocasionó una pausa en los vuelos tripulados de la URSS. No obstante, el programa Soyuz-Salyut continuó hasta 1986, años en los que nuevas estaciones y naves iniciaron viajes hacia la órbita terrestre. El Salyut 2 y las siguientes cinco estaciones espaciales tenían como propósito las investigaciones científicas. La última estación, Salyut 7, fue habitada por 3.216 días desde su lanzamiento en 1982 hasta 1999 (Ciudad Futura, 2010).

\section{Skylab, el laboratorio del cielo}

Los estadounidenses también realizaron sus propios esfuerzos por fabricar su propia estación espacial fija en órbita de la Tierra, con el fin de que fuera habitada por astronautas. La Skylab era un enorme objeto espacial, una estación experimental de 77,5 toneladas, que permaneció en órbita terrestre por seis años. El principal objetivo del Skylab consistía en demostrar que los seres humanos podían vivir y trabajar por fuera de la Tierra durante períodos relativamente prolongados de tiempo. Además, tenía el fin de ampliar información sobre la astronomía solar. Tres tripulaciones de tres astronautas cada una residieron en el Skylab en misiones de 28, 59 y 84 días respectivamente. Durante tales períodos de tiempo se llevaron a cabo más de trescientos experimentos y pruebas, en los que se analizaron los efectos de las erupciones solares sobre la Tierra, así como exámenes médicos que investigaban las demandas fisiológicas de los astronautas en el espacio ultraterrestre. Debido al prolongado efecto de la ingravidez en 
sus cuerpos, los astronautas se encontraban demasiado débiles, incluso para ponerse de pie al regresar de sus largas misiones y, por tal motivo, los equipos para ejercitarse se convirtieron en un requisito para todas las misiones espaciales de larga duración (Discovery Channel).

\section{Mir, paz en el espacio}

La estación espacial Mir significó no solo un éxito debido a la subsistencia de los astronautas durante largos períodos de tiempo en el espacio, sino también por haber sido la primera vez que se da una colaboración entre la agencia espacial rusa y la agencia espacial estadounidense en medio de las rivalidades de la época.

La estación espacial Mir fue una evolución de las misiones Salyut. La Mir en órbita conformaba un laboratorio científico amplio y habitable en el espacio exterior. Su construcción en el espacio comenzó en 1986 y finalizó en 1996. Durante ese período de diez años se adicionaron a la estación diversos módulos que permitieron la ampliación de las zonas donde habitaban y trabajaban los astronautas. Luego de que se adhirieran las partes finales a la estación, fue la mayor estructura espacial construida hasta entonces, con una masa total de más de 250 toneladas. La Mir permaneció constantemente habitada hasta 1999 por astronautas y científicos de varias nacionalidades, hasta el final de su vida útil. Esta estación fue un éxito total al demostrar que una persona podía vivir durante más de un año en la estructura. Este récord fue del cosmonauta Valeri Polyakov, que además de constituir un gran hito, aportó datos fundamen- tales con vistas a las misiones de larga duración que pudieran llevarse a cabo en un futuro.

Esta estructura espacial fue la cuna de numerosos descubrimientos, pero al llegar el fin de su vida útil, tuvo lugar su destrucción programada, haciendo que se precipitara contra la Tierra. Así, finalizaron varios años de polémica sobre la utilidad real de la estación, puesto que ya no se le inyectaba la misma cantidad de recursos que se invertían anteriormente, debido a que la agencia espacial rusa pasaba por una crisis, por lo que su mantenimiento era deficiente, lo que causó numerosos riesgos a las tripulaciones que la habitaron (Santillana, 2006).

\section{La ISS}

La actual Estación Espacial Internacional (ISS, por sus siglas en inglés) es el siguiente paso en la colonización del espacio, además de ser el proyecto más complejo realizado hasta el momento, tanto por su tamaño como por los experimentos científicos que se planean.

Los orígenes de la ISS vienen desde el programa espacial Freedom, Ilevado a cabo por los Estados Unidos. En 1984, el presidente Ronald Reagan manifestó la intención oficial de desarrollar una estación orbital permanente, que se conocería como Estación Espacial freedom. Al proyecto fueron invitados países como Canadá, Europa y Japón. No obstante, en respuesta a sucesivas limitaciones presupuestarias, la construcción de la nave tardó unos años más y la NASA, en cabeza de Dan Goldin, pidió un rediseño de la estación en un plazo compren- 
dido entre primavera y verano de 1993. En un principio se desarrollaron varias alternativas para el programa espacial, de las cuales fue seleccionada la primera, nombrada por Bill Clinton como Estación Alfa, que luego de algunas modificaciones se convirtió en la Estación Espacial Internacional.

Las negociaciones entre los gobiernos de los Estados Unidos y Rusia se dieron en torno al tema de la cooperación. Una vez superado el final de la Guerra Fría, para finales de 1993 se invitó oficialmente a Rusia a participar como un miembro más en el proyecto espacial, invitación que el país europeo aceptó. Actualmente, en el proyecto de la Estación Espacial Internacional trabajan 16 Estados: EE. UU., Canadá, Rusia, Japón, Italia, Bélgica, Holanda, Dinamarca, Noruega, Francia, España, Alemania, Gran Bretaña, Suecia, Suiza y Brasil. La primera tripulación se instaló en 2000, y desde entonces la ISS ha estado habitada siempre (Estación Espacial, 2007).

\section{El presente de la exploración espacial}

\section{La exploración en Marte: La misión Curiosity}

La misión Curiosity es el proyecto más reciente y del que más se habla en estos días, en relación con la exploración al planeta rojo. Fue lanzado el 26 de noviembre de 2011, con un aterrizaje exitoso en Marte el 6 de agosto de 2012. Curiosity es un vehículo con seis ruedas, un brazo robótico y una pequeña pala que le permite tomar muestras del polvo que cubre el suelo marciano, este vehículo lleva herramientas científicas más avanzadas que los de las otras misiones anterio- res dirigidas a Marte. Esta estructura tiene cuatro objetivos principales: determinar la existencia de vida en Marte, definir el clima de Marte, determinar la composición de su suelo y tomar información que contribuya a la exploración humana de Marte en un futuro. En la actualidad, la misión ha tomado muestras y ha encontrado que el polvo de la superficie de Marte contiene un $2 \%$ de agua y otros materiales orgánicos. La muestra que se analizó en este estudio, en el que participan 34 científicos, está conformada por tierra y polvo recogidos de una zona arenosa del planeta rojo, llamada Rocknest. La muestra recogida fue calentada a $835^{\circ} \mathrm{C}$, lo que posibilitó determinar que también hay presentes elementos como el cloro y el oxígeno, probablemente clorato o perclorato, que ya se había detectado en otras zonas de Marte.

No obstante, los hallazgos del Curiosity no se limitan a las tomas de muestras señaladas. El Rover viajó a través de 1.6 kilómetros de la superficie árida de Marte, durante más de un año en el planeta, y recolectó una numerosa cantidad de datos y envió a la Tierra más de 36.700 imágenes completas y 35.000 imágenes en miniatura.

La misión Curiosity ha tenido importantes momentos históricos, entre ellos los primeros minutos de la llegada a Marte, los cuales fueron denominados como "los minutos del terror", ya que se temía que el aterrizaje terminara en una catástrofe, pero contrario a ello el descenso fue exitoso. Un segundo momento histórico ocurrió en octubre de 2012, cuando el robot tomó la primera fotografía de Marte y la envió a la Tie- 
rra. Además, mientras el Curiosity ha estado en superficie marciana, ha captado imágenes de varios eclipses de las lunas del planeta rojo (Redacción Central, 2013).

\section{Tiangong 1}

Hasta el momento, los protagonistas de la carrera espacial han sido los norteamericanos y los rusos. Sin embargo, actualmente existe otro contendiente dentro de la competencia por la exploración del espacio. El Tiangong 1 es el primer módulo de la Estación Espacial China con presencia permanente en órbita terrestre. El módulo fue lanzado el 29 de septiembre de 2012 y está diseñado para recibir tres vehículos visitantes. Es importante señalar que el programa espacial chino no se quedará únicamente con este primer módulo, ya que se prevé que este será reemplazado por el Tiangong 2 en el 2013, un laboratorio más amplio y sofisticado, y este a su vez será sustituido por el Tiangong 3 , con el fin de dar los últimos pasos hacia una gran estación espacial en la órbita baja de la Tierra. Los investigadores chinos han manifestado recientemente que su nueva estación espacial será tan grande como la estación Skylab estadounidense, que orbitó la Tierra por varios años; se espera que para el 2020 esté en pleno funcionamiento.

El Tiangong está equipado con varias cargas útiles, que pueden funcionar sin necesidad de que la tripulación se encuentre a bordo, y además posee un conjunto de instrumentos de observación de la Tierra (Blau, 2011).

\section{El cohete Naro}

A principios de 2013, Corea del Sur logró enviar exitosamente al espacio su cohete Naro-1, el primer objeto fabricado con tecnología local, luego de dos intentos que fracasaron en 2009 y 2010; esto constituye una gran hazaña para el país asiático. Este nuevo hito espacial supondría el ingreso de Corea del Sur en el grupo selecto de las potencias espaciales que han alcanzado el logro de poner en órbita un satélite, gracias a tecnología nacional.

Este proyecto surcoreano ha estado plagado de obstáculos; se dio bajo el marco de la guerra técnica con su vecino Corea del Norte, quien a pesar de tener dificultades económicas, logró llevar a cabo la misma hazaña tan solo unos meses atrás. La poderosa Corea del Sur, cuarta economía asiática, había enviado hasta hoy al espacio alrededor de diez satélites, pero todos ellos lanzados desde instalaciones extranjeras.

\section{ESFUERZOS EN LATINOAMÉRICA}

A lo largo de este artículo se han recordado los diferentes logros de los Estados Unidos, países europeos y asiáticos en relación con la exploración del espacio. No obstante, es necesario mencionar que, durante los últimos años, América Latina ha participado en estas actividades por medio de iniciativas de sus Estados, que tienen el fin de poner en órbita sus propios satélites.

Todos los proyectos han sido diferentes, pero tienen un propósito en común: lograr independizarse de los demás Estados que poseen sa- 
télites de telecomunicaciones. En torno a este fin, se han ideado varios planes como el Plan Nacional de Banda Ancha de Brasil, Argentina Conectada, e-México, entre otros proyectos. Es así que algunos de estos nuevos programas buscan aumentar las capacidades tecnológicas nacionales, con la fabricación de satélites propios. No obstante, muchos países latinoamericanos cuentan con apoyo de China, país que está fuertemente interesado en participar en una industria ampliamente dominada por los norteamericanos y europeos. Poco a poco, el lanzamiento de los satélites locales dará origen a un nuevo período para los latinoamericanos, y por cuenta de ello se hará un breve recorrido por las iniciativas más sobresalientes.

\section{Brasil}

Brasil ha dado pasos importantes con su Programa Nacional de Actividades Espaciales, con miras a 2021, y con un presupuesto de unos US\$ 4.500 millones. EI PNAE cree que llegar al espacio y ubicar satélites propios allí es necesario para mejorar las telecomunicaciones, tener mayor información, hacer mejor uso de los recursos naturales, mejorar la vigilancia de las fronteras y mejorar la promoción de la inclusión social. Actualmente se está desarrollando el proyecto del Satélite Geoestacionario de Defensa y Comunicaciones Estratégicas (SGDC), que será elaborado por la empresa Thales Alenia Space, y que tiene como propósito secundario servir de modelo para la realización de los demás modelos. Es importante señalar que la extensión de estos proyectos usualmente trae obstáculos. En este caso particular, la construc- ción de la plataforma de lanzamiento brasileña sufrió varios atrasos, debido a la resistencia de pueblos nativos a abandonar el lugar en la que se edificará la base, y debido a varios permisos que los Estados Unidos no han concedido para la utilización de materiales hechos en ese país (Gnius, 2013).

\section{Colombia}

Hace algunos años Colombia lanzó una licitación internacional con el fin de operar un satélite de telecomunicaciones propio, denominado SatCol. Sin embargo, el concurso no tuvo ningún ganador, ya que los candidatos no cumplían con muchos de los requisitos requeridos por el Ministerio de la Información y las Comunicaciones, por lo que se declaró desierto (El Tiempo, 2009). En este momento, Colombia aún no posee un satélite propio, ni ha vuelto a lanzar alguna licitación. Por cuenta de ello, el Plan Compartel, con el que se pretendía hacer llegar información a las zonas más remotas del territorio colombiano, ha quedado en una pausa indefinida. No obstante, algunas de las medidas que se pretendían tomar, una vez fuera construido y puesto en órbita el satélite, se han incluido en el Plan Vive Digital que se lleva a cabo actualmente (Ministerio de Teconologías de la Información y las Comunicaciones).

\section{México}

Actualmente, El Estado mexicano planea poner en órbita terrestre tres satélites, el Mexsat 1 y el Mexsat 2, cuya labor se encaminará a las comunicaciones móviles, y el Mexsat 3, que se 
encargará de las comunicaciones fijas, cuyos lanzamientos se tenían planeados para finales de 2013 y 2014. Al igual que Brasil, México también vio la necesidad de construir una estación espacial en tierra, para poder controlar y monitorear a los satélites en órbita. La inversión que ha realizado el Estado mexicano en este proyecto sobrepasa los US\$ 1.000 millones, ya que la importancia de este sistema satelital revolucionará la historia de las telecomunicaciones en México. Suministrará servicios telefónicos, de banda ancha, telemedicina, teleducación, soporte para emergencias, comunicaciones para la seguridad nacional y de lucha contra la delincuencia (Agencia Espacial Mexicana, 2008).

\section{Venezuela}

Este país vecino creó la compañía Venesat, que controla su propio satélite, el Simón Bolívar 1, de fabricación china y cuyo lanzamiento se dio el primero de noviembre de 2008. La actividad de este objeto está exclusivamente destinada a clientes venezolanos, puesto que para el Estado es prioridad el desarrollo local. El Simón Bolívar es empleado especialmente para servicios de comunicaciones en zonas rurales apartadas. En los últimos años, además de su satélite de la órbita geoestacionaria, el Estado venezolano puso en órbita el Francisco de Miranda, cuya función es la teleobservación de la Tierra desde una órbita baja, con el fin de colaborar con la actualización de la cartografía nacional (Gnius, 2013).

\section{EL FUTURO DE LA EXPLORACIÓN ESPACIAL: ¿QUÉ NOS ESPERA?}

Es cierto que la historia no ha terminado de escribirse, cada día se dan adelantos que nos sorprenden. Tal vez algún día se hagan realidad las historias fantásticas que escritores como Isaac Asimov, Frank Herbert y Philip K. Dick han relatado en relación con la visita de extraterrestres y la exploración de planetas lejanos. Sin embargo, aún no podemos ir tan lejos, pero por ahora lo que sí es cierto es que existe el programa SETI (Search for ExtraTerrestrial Intelligence), que tiene como propósito detectar la presencia de vida inteligente más allá de la Tierra. Su estrategia es la audición de las emisiones de ondas de radio emitidas desde el espacio, que son captadas por antenas en la Tierra. La cantidad de señales que percibe diariamente este radiotelescopio es significativa, y con esto se comprueba que el espacio ultraterrestre es un lugar muy "ruidoso". Sin embargo, todas estas señales deben ser procesadas informáticamente, por tal razón, se ha establecido un método muy sencillo: por medio de Internet, las personas desde sus hogares descargan una pequeña aplicación, que se instala en su computador y en los tiempos de inactividad de la máquina se realizan los cálculos y se envían a la sede del SETI. Además, ahora es posible vivir una larga temporada fuera de la Tierra en condiciones de poca gravedad o de ingravidez total. Sin embargo, esto trae consigo problemas metabólicos para los astronautas. Desde el punto de vista científico, esto no es nada grave, pero surgen otros problemas más allá de lo biológico, y es 
si un ser humano podría sobrevivir psicológicamente en un espacio tan pequeño como el de una nave espacial. Además, los problemas no se limitan a tales cuestionamientos, surgen más preguntas del tipo: ¿Cómo tendría que ser una nave capaz de llegar a Marte y volver, trayendo a la tripulación sana y salva? ¿Cuánto tiempo resistirían los astronautas en Marte? Muchos de los experimentos que se realizan actualmente en la ISS contribuirán a despejar esas dudas (Santillana, 2006).

\section{CONCLUSIONES}

La simple curiosidad que mueve al hombre no tiene límites, y ha alcanzado fronteras inimaginables. Los sumerios se preguntaban por los planetas, la Luna y el sol, también lo hacian los griegos, egipcios y mayas; de allí hasta el programa Curiosity han pasados varios miles de años. Sin embargo, la necesidad del hombre de saber qué hay más allá de las nubes que ve en el cielo no ha menguado, por el contrario, ha crecido. Las naciones han invertido recursos con el único propósito de saber qué ocurre en lugares que no podemos ver con nuestros propios ojos. Millones de dólares se han perdido por causa de misiones fallidas, pero el hombre no deja de intentarlo y cada día busca la manera de corregir los errores.

Lo más importante e interesante del inicio de la carrera espacial es que se dio en un contexto de guerra y tensión política, pero la exploración espacial ocurrió pacíficamente. Los Estados Unidos y la Unión Soviética estaban expectantes a ataques de su rival, pero finalmente, podría decirse, tal hostilidad se tradujo en una competencia sobre quién llegaba más lejos en la exploración espacial. Ni la Unión Soviética se retiró derrotada, ni los Estados Unidos desertaron de su propósito, ambos alcanzaron objetivos significativos que revolucionaron la historia de la humanidad. Los soviéticos lograron llevar al hombre fuera del espacio terrestre por primera vez, y los norteamericanos fueron quienes promovieron las primeras pisadas del hombre en la Luna. La frase que empleó el astronauta Neil Armstrong - «Un pequeño paso para el hombre, un gran paso para la humanidad»- aplica para cada nuevo avance, cada nuevo descubrimiento y cada lanzamiento; son pequeños pasos para el hombre, pero para la humanidad significan un futuro mejor. Por otra parte, es necesario señalar aquí lo que se planteó en la introducción sobre la necesidad que vio la comunidad internacional de crear tratados para regular las actividades espaciales, disolver tensiones y establecer además principios generales de uso pacífico, no apropiación y cooperación, que deben ser respetados por todos los países. En este sentido, podría interpretarse que, como el inicio de la exploración espacial se dio en el marco de la Segunda Guerra Mundial con fines bélicos, no podría permitirse que se siguieran llevando a cabo avances con fines de destrucción. A partir de allí se procuraron crear relaciones completamente cordiales que estuvieran reguladas por instrumentos internacionales, más si se tiene en cuenta que en pocos años la exploración se dio en pasos asombrosamente acelerados, por lo que no podía perderse tiempo para crear una 
reglamentación que prohibiera cualquier abuso por parte de un país.

Si bien actualmente existen diferencias entre Estados con respecto a ciertos aspectos, como la delimitación del espacio ultraterrestre, es claro que las diferencias entre naciones no son motivo para creer en la intención de emplear la ventaja que algunos Estados poseen más allá de la Tierra para perjudicar a los demás países; todo lo contrario, los Estados están tratando de crear un ambiente de bienestar en todo el mundo, que gracias a la exploración ha agilizado miles de actividades realizadas por el hombre de manera significativa.

Por otra parte, nadie asegura que no pueda ocurrir en un futuro otra guerra de magnitud mundial. Sin embargo, las tensiones y posibles intenciones de emplear el espacio ultraterrestre para fines armamentistas está absolutamente prohibidas, porque ya existió previamente un contexto de guerra en el que se regularon las relaciones pacíficas.

En este orden de ideas, no podría concebirse una regulación en materia de actividades espaciales, sin unos hechos que lo precedan. Es decir, no tendría ningún sentido que se creara regulación para situaciones que no suceden. Por ejemplo, no tendría ninguna utilidad el Acuerdo que debe regir las actividades de los Estados en la Luna y otros cuerpos celestes si el ser humano no hubiera llegado a la Luna ni existieran esperanzas de poder, algún día cercano, visitar otros planetas. Así, se hace necesario entender el contexto histórico de la exploración espacial para entender la esencia misma de la regulación de las actividades ultraterrestres.

\section{Referencias}

2da-guerra-mundial.com.ar. El Día D. Desembarco en Normandia. La muralla del Atlántico. Recuperado de http://www.2da-guerramundial.com.ar/desembarcoennormandia. php

Agencia Espacial Mexicana (2008). Recuperado de http://www.aexa.divaac.org/div05.html

Amiguet Molina, T. M. (3 de noviembre de 2012). Laika, una astronauta muy perruna. La Vanguardia, recuperado de http://www.lavanguardia.com/hemeroteca/20121103/54354115435/laika-sputnikii-perros-astronautica-rusia-viajes-espacialescarrera-del-espacio.html

Aracil, R., Oliver, J. y Segura, A. (1998). El mundo actual. De la Segunda Guerra Mundial a nuestros días. Barcelona: Edicions Universitat de Barcelona.

Asosiación de Amigos de la Astronomía. Historia de la Astronomía. Atroelda.com, recuperado de http://www.astroelda.com/HTML/HISTORIA/HISTORIASTRONOMIA.htm

Bello Janeiro, D. (4 de marzo de 2006). Churchill y el telón de acero, recuperado de http://www.lavozdegalicia.es/hemeroteca/2006/03/04/4570651.shtml 
Belmonte, J. A. (2013). La astronomía en Egipto. National Geographic.com, recuperado de http://www.nationalgeographic.com.es/articulo/historia/grandes_reportajes/8198/astronomia_egipto.html?_page=2

Blau, P. (2011). Tiangong 1 - Spacecraft information. Recuperado de http://www.spaceflight101.com/tiangong-1-info.html

Bowen, R. (3 de julio de 2013). Historia del desconocido Burán, el avión espacial soviético. Guioteca, recuperado de http://www. guioteca.com/exploracion-espacial/la-desconocida-historia-del-avion-espacial-sovieticoburan/

Christy, R. Luna - Exploring the moon: The mission of Luna 2. Zarya: Soviet, Russian and international Space Flight, recuperado de http://www.zarya.info/Diaries/Luna/Luna02. php

Ciudad Futura (23 de diciembre de 2010). Salyut 1: La primera estación espacial de la historia. Historia e infografía. Naukas, recuperado de http://naukas.com/2010/12/23/salyut-1-laprimera-estacion-espacial-de-la-historia-historia-e-infografia/

CTV. El Programa Zond Soviético y la continuación de la Luna. Canal Ciencia, recuperado de http://www.ctv.es/USERS/ivanfh/espacio/ luna13.htm

Discovery Channel (2014). Grandes misiones de la NASA. Recuperado de http://www.tu- discovery.com/web/nasa/orbita/tripulados/ gemini/?page $=2$

-. Skylab. Grandes misiones de la NASA, recuperado de http://www.tudiscovery.com/web/ nasa/orbita/estaciones_espaciales/skylab/

-. Transbordadores. Explorando el espacio, recuperado de http://www.tudiscovery.com/ guia_espacio/explorando/transbordadores/

Duvan, S.A de ediciones (1970). Gran Enciclopedia del Mundo. Bilbao: Marín, S.A.

EcuRed.cu. Batalla de Inglaterra. EcuRed: conocimiento con todos y para todos, recuperado de http://www.ecured.cu/index.php/Batalla_ de_Inglaterra_\%28Segunda_Guerra_Mundial\%29

Educar.org. De la Tierra a la Luna. Bibliotecas virtuales: comunidad virtual literaria. Recuperado de http://www.bibliotecasvirtuales. com/biblioteca/literaturafrancesa/julioverne/delatierraalaluna/

El Nuevo Diario (4 de Noviembre de 2013). Nicaragua tendrá listo su satélite en el tercer trimestre de 2016. El Nuevo Diario, recuperado de: http://www.elnuevodiario.com.ni/nacionales/301033

El Tiempo (2009). SatCol, proyecto importante para el país. El Tiempo, recuperado de http:// www.eltiempo.com/archivo/documento/ CMS-5317807 
Enciclopedia Salvat (1971). Adolfo Hitler. BarceIona: Salvat Editores S.A.

estacionespacial.com (21 de octubre de 2007). Historia de la ISS: un proyecto ambicioso. Recuperado de http://www.estacionespacial. com/historia.php

Ferreira Lorenzo, M. A. (28 de octubre de 2012). La misión Apolo 17. Recuperado de http:// www.viajealaluna.com/programa-apolo/apo|o-17|

García Sagario, G. (12 de noviembre de 2012). Vanguard I, el satélite más antiguo en órbita. Zemiorka.blogspot, recuperado de http:// zemiorka.blogspot.com/2012/11/vanguard1-el-satelite-mas-antiguo-en.html

- (12 de noviembre de 2012). Vanguard 1, el satélite más antiguo en órbita. Zemiorka, recuperado de http://zemiorka.blogspot. com/2012/11/vanguard-1-el-satelite-masantiguo-en.html

Gnius, J. (11 de febrero de 2013). El espacio se puebla con satélites latinoamericanos. Recuperado de http://www.signalstelecomnews. com/index.php/analisis-y-columnas/5389el-espacio-se-puebla-con-satelites-latinoamericanos

Halifax, L. (1939). El ultimátum británico a Alemania el 3 de septiembre de 1939. Historia del siglo $X X$, recuperado de http://www.historiasiglo20.org/TEXT/ultimatumgb1939.htm
Harvey, B. (1996). The new Russian space programme from competition to collaboration. Chichester: John Wiley \& Sons.

Hermans Killam, L. Pregúntale a un astrónomo. Recuperado de http://legacy.spitzer.caltech. edu/espanol//edu/askkids/redspot.shtml

Historia del siglo XX. El Desembarco de Normandía. HistoriasigloXX.org, recuperado de : http://www.historiasiglo20.org/GLOS/normandia.htm

Holmes, J. (1966). La conquista de la Luna. México: Trillas.

Instituto de Tecnologías Educativas (2010). Los orígenes de la Guerra Fría. Historiasiglo20. org, recuperado de http://www.historiasiglo20.org/HM/6-1a.htm

Kennedy, J. F. (Septiembre de 1962). Discurso en la Universidad Rice sobre el Programa Espacial del país. Houston, Texas, Estados Unidos.

Kolosimo, P. (1969). Sombra en las estrellas. Barcelona: Plaza y Janés, S.A.

La Jornada (15 de noviembre de 2012). Acuerdan construcción del satélite nicaragüense en dos años. La Jornada, recuperado de: http://www.lajornadanet.com/diario/archivo/2012/noviembre/15/1.php

Libertad Digital (20 de agosto de 2010). La Viking 1, la primera misión que aterrizó en Marte, cumple 35 años. Recuperado de http:// 
www.libertaddigital.com/ciencia/la-viking1-la-primera-mision-que-aterrizo-en-martecumple-35-anos-1276399982/

Ministerio de Teconologías de la Información y las Comunicaciones. El Plan Vive Digital. Recuperado de http://www.mintic.gov.co/portal/vivedigital/612/w3-propertyvalue-6106. html

National Aeronautics and Space Administration (28 de julio de 2012). Mars Global Surveyor. Recuperado de http://mars.jpl.nasa.gov/ mgs//

- (16 de agosto de 2013). Luna 1. National Space Science: Data Center, recuperado de http://nssdc.gsfc.nasa.gov/nmc/masterCatalog.do?sc=1959-012A

- (26 de agosto de 2014). Vostok 1. Recuperado de http://nssdc.gsfc.nasa.gov/nmc/spacecraftDisplay.do?id=1961-012A

- (2013). Surveyor 1. National Space Science: Data Center, recuperado de http://nssdc. gsfc.nasa.gov/nmc/spacecraftDisplay. do?id=1966-045A

Nieves, J. M. (22 de septiembre de 2013). La Voyager 1 cruza la última frontera del Sistema Solar. $A B C$, recuperado de http://www. abc.es/ciencia/20130922/abci-mision-voyager-201309211929.html

Novosti, R. (2010). La primera caminata espacial. Recuperado de http://rusopedia.rt.com/ ciencia_y_tecnica/espacio/issue_230.html
Ocaña, J. C. (2003). La Guerra Fría. Historia de las relaciones internacionales en el siglo XX. Recuperado de http://www.historiasiglo20. org/GF/1945-47.htm

Paralibros.com. Misión Apolo 11. «Houston, aquí Base Tranquilidad, el Aguila ha alunizado». Conquista de la Luna. Recuperado de http://www.paralibros.com/passim/p20spc/pg2069ap.htm

Portalplanetasedna.com.ar. Segunda Guerra Mundial. Resumen causas, desarrollo y consecuenciasn de la Segunda Guerra Mundial. Planeta Sedna, recuperado de http://www. portalplanetasedna.com.ar/guerra2.htm

Posada-Awafford, Á. (2009). El telescopio: la historia del invento que revolucionó la ciencia. Revista Muy Interesante, recuperado de http://www.muyinteresante.es/ciencia/articulo/el-telescopio-la-historia-del-invento-querevoluciono-la-ciencia

Proyecto Gutenberg. The First Men in the Moon by H. G. Wells. Gutenberg.org, recuperado de http://www.gutenberg.org/ebooks/1013

Redacción Central (9 de octubre de 2013). Marte, la otra frontera Curiosity realizó grandes hallazgos en el planeta rojo. Los Tiempos.

Sampedro, J. (20 de agosto de 2005). La Novela de Kepler. El País, recuperado de http:// elpais.com/diario/2005/08/20/revistaverano/1124488821_850215.html 
Santillana (2006). Explorando el espacio. En Starmus (31 de marzo de 2014). Un grupo de leSantillana, Enciclopedia del estudiante (pp. 282-283). Buenos Aires: Santillana.

Sanz, E. (12 de abril de 2011). Yuri Gagarin, el primer ser humano en el espacio. Revista Muy interesante, recuperado de http://www. muyinteresante.es/historia/articulo/yuri-gagarin-el-primer-ser-humano-en-el-espacio

Sarkissian, J. One Giant Leap: The Landing. Recuperado de http://www.parkes.atnf.csiro. au/news_events/apollo11/one_giant_leap. html

Shelton, W. (1969). Soviet space exploration. The first decade. Londres: Arthur Barker Ltd.

Sondas espaciales (18 de julio de 2011). Luna 9. Sondas espaciales.com, recuperado de http://www.sondasespaciales.com/index. php/Luna_9

gendarios cosmonautas liderados por Alexei Leonov participarán el el Festival Starmus, recuperado de http://www.starmus.com/es/ un-grupo-de-legendarios-cosmonautas-rusosliderados-por-alexey-leonov-participaran-enel-festival-starmus/

Vanguardia.com (18 de julio de 2011). John Glenn, pionero de la exploración espacial de EU cumple 90 años. Vanguardia, recuperado de http://www.vanguardia.com/ historico/113406-john-glenn-pionero-de-laexploracion-espacial-de-eu-cumple-90-anos

Vargas, L. (12 de septiembre de 2007). Explorer I, primer satélite de Estados Unidos. axt.4t, recuperado de http://www.axt.4t.com/space/history/explorer1.html

Zak, A. (2014). Burán. Recuperado de http:// www.russianspaceweb.com/buran.html 